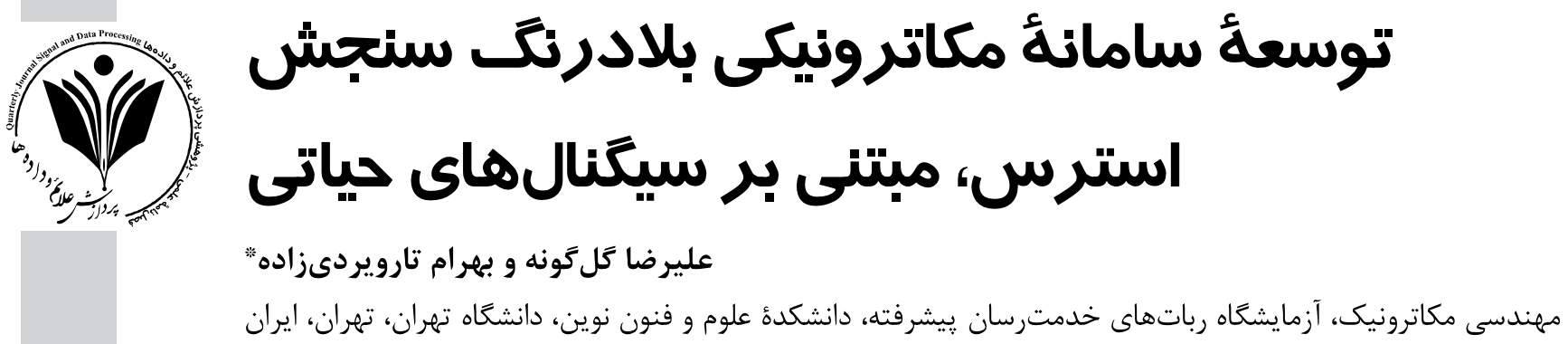

جكيده

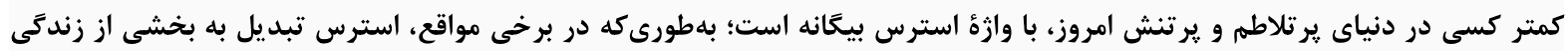

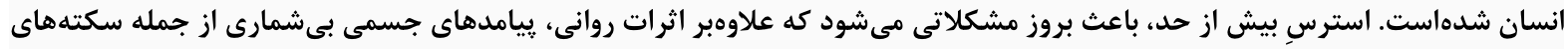

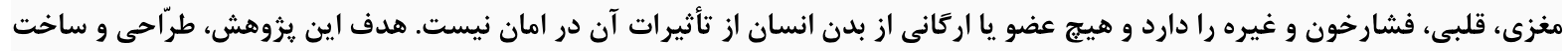

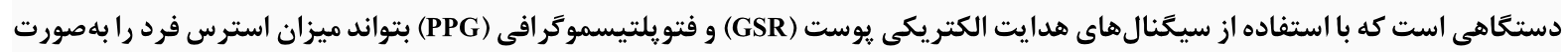

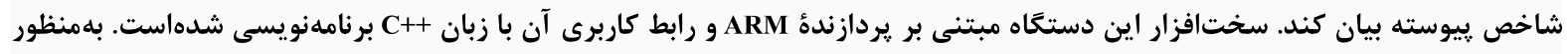

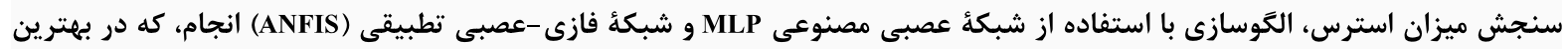

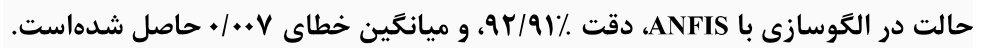

وازًَان كليدى: سيكنال هاى حياتى، فتويلتيسموكرافى، هدايت الكتريكى يوست، شبكهُ عصبى مصنوعى، شبكهُ فازى-عصبى تطبيقى

\title{
Development of a Mechatronics System to Real-Time Stress Detection Based on Physiological Signals
}

\author{
Alireza Golgouneh and Bahram Tarvirdizadeh* \\ Advanced Service Robots (ASR) Lab., Department of Mechatronics Engineering, Faculty of \\ New Sciences and Technologies, University of Tehran, Tehran, Iran
}

\begin{abstract}
Stress has affected human's lives in many areas, today. Stress can adversely affect human's health to such a degree as to either cause death or indicate a major contributor to death. Therefore, in recent years, some researchers have focused to developing systems to detect stress and then presenting viable solutions to manage this issue.

Generally, stress can be identified through three different methods including (1) Psychological Evaluation, (2) Behavioral Responses and finally (3) Physiological Signals. Physiological signals are internal signs of functioning the body, and therefore nowadays are commonly used in various medical and non-medical applications. Since these signals are correlated with the stress, they have been commonly used in detection of the stress in humans. Photoplethysmography (PPG) and Galvanic Skin Response (GSR) are two of the most common signals which have been widely used in many stress related studies. PPG is a noninvasive method to measure the blood volume changes in blood vessels and GSR refers to changes in sweat gland activity that are reflective of the intensity of human emotional state.
\end{abstract}

Corresponding author

* نويسندة عرهدهار مكاتبات 
Design and fabrication of a real-time handheld system in order to detect and display the stress level is the main aim of this paper. The fabricated stress monitoring device is completely compatible with both wired and wireless sensor devices. The GSR and PPG signals are used in the developed system. The mentioned signals are acquired using appropriate sensors and are displayed to the user after initial signal processing operation. The main processor of the developed system is ARM-cortex A8 and its graphical user interface (GUI) is based on $\mathrm{C}++$ programming language. Artificial Neural Networks such as MLP and Adaptive Neuro-Fuzzy Inference System (ANFIS) are utilized to modeling and estimation of the stress index. The results show that ANFIS model have a good accuracy with a coefficient of determination values of 0.9291 and average relative error of 0.007 .

Keywords: physiological signals, Photoplethysmography, galvanic skin response, artificial neural networks, ANFIS

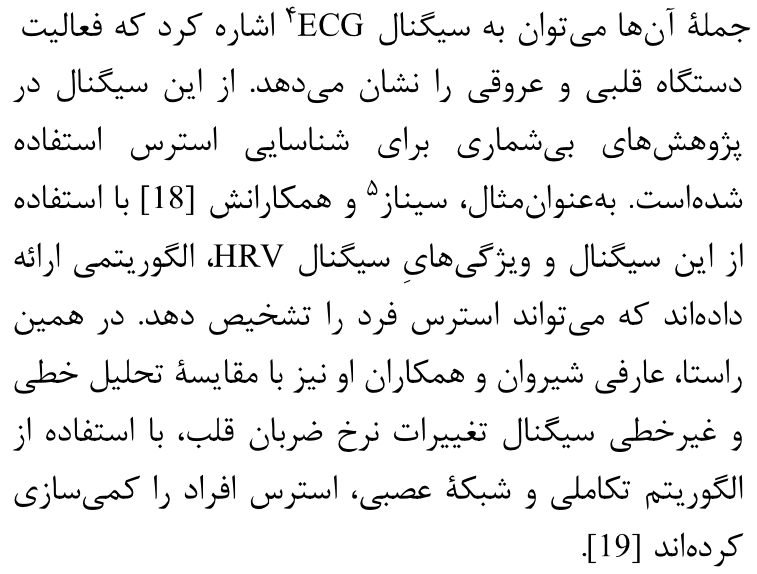

از ديخر علائم فيزيولوزيكى استرس، مىتوان به

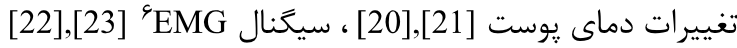

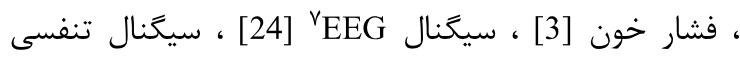

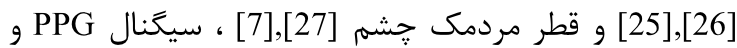

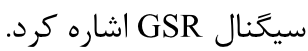

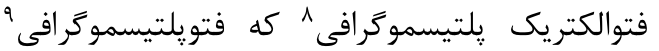

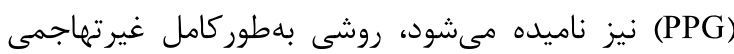
براى اندازمخيرى تغييرات حجم خون و وآشكارسازى موج

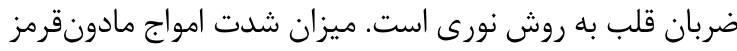
عبورى از بدن بر اثر جذب يا بازتاب تغيير يافته و و با فيا

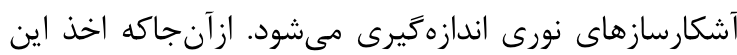

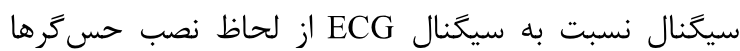

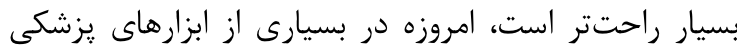

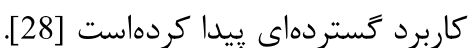

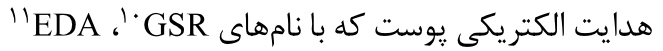

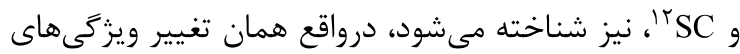

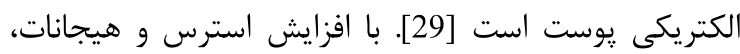

\footnotetext{
${ }^{4}$ Electrocardiography

${ }^{5}$ Cinaz

${ }^{6}$ Electromyography

${ }^{7}$ Electroencephalography

${ }^{8}$ Photoelectric plethysmography

${ }^{9}$ Photoplethysmography

${ }^{10}$ Galvanic Skin Response

${ }^{11}$ Electrodermal Activity

${ }^{12}$ Skin Conductance
}

\section{|- مقدمه}

استرس يكى از مهمترين مسائلى است كه هر فرد بهطور

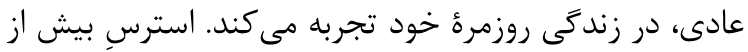

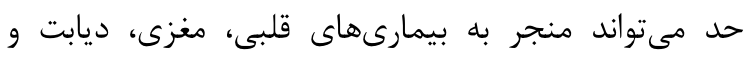
همجنين، تضعيف دستخاه ايمنى بدن شود [1].

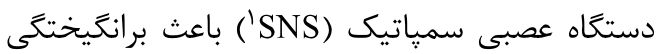

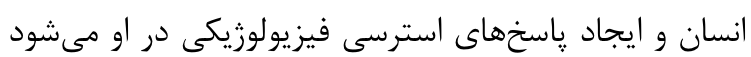
[2],[1]. ياسخهاى فيزيولوزيكى، به آن دسته از اعمال طبيعى إنى

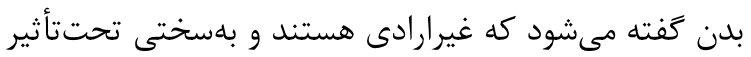
عوامل خارجى قرار مى ئيرند [4]. افزايش عصبانيت، اضطراب،

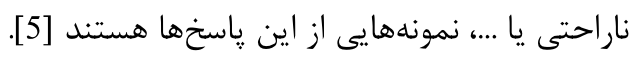

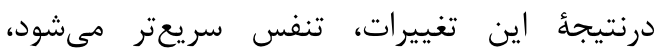
فشارخون افزايش [6] و ويزگى هاى صوتى تغيير مى كنند، دماى يوست دست و ڤا [7] و ميزان تغييرات نرخ قلب كاهش مى يابند و قطر مردمك جشم نيز تغيير ('HRV)

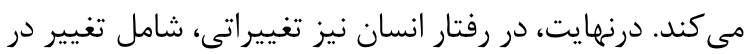

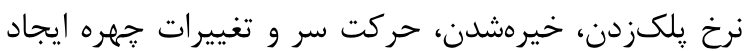
مىشود [8]. بهوطوركلى، استرس را مىتوان از سه روشي ارزيابى

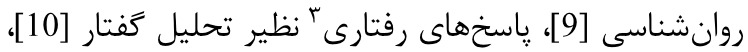
ميزان و نحوء استفاده از تلفن همراه [11]، استفاده از رايانه

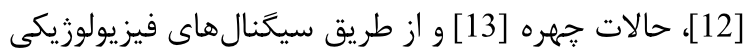

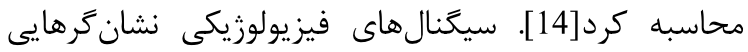
هستند كه اطلاعات دقيقى راجع به بدن افراد مىدهند [15]؛ و به همين دليل، امروزه در بسيارى از وسايل و ابزارهاى يزشكى و غير يزشكى از آنها استفاده شدهاست ([15] و [16]).

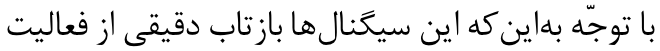

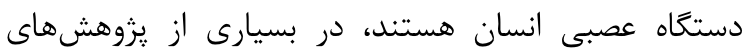

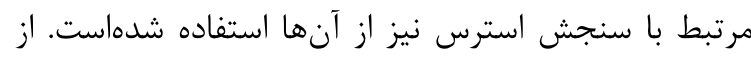

\footnotetext{
${ }^{1}$ Sympatic Nervous System

${ }^{2}$ Heart Rate Variability

${ }^{3}$ Behavioral Responses
} 


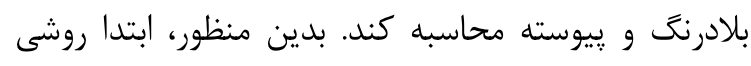

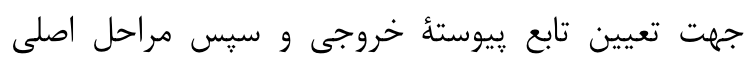
الكوسازى و ساخت شرح داده شدهاست. دستخاه ساختهشده

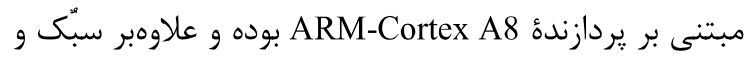

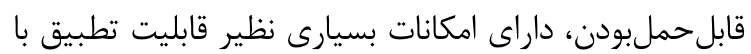

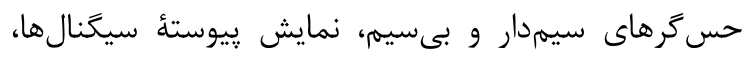

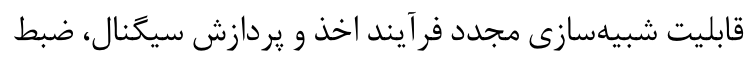
و קֶخش صدا، ذخيرة اطلاعات شخصى افراد، امكان يرسش و

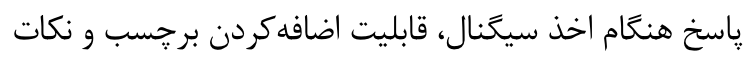
بر روى سيخنالها در زمانهاى مشخص و بسيارى از موارد

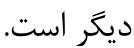

\section{r- سامانهُ تشخيص استرس}

همانطوركه اشاره شد، هدف اصلى از انجام اين بروهش،

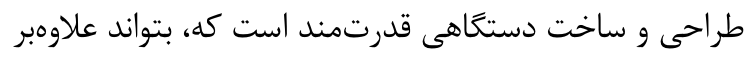

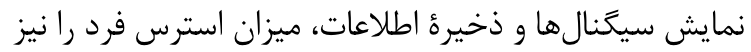

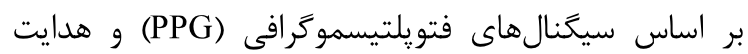
الكتريكى يوست (GSR) محاسبه كند و نمايش دهد. بنابراين، بلمنظور ايجاد קنين دستًاهى كه سبك، كممصرف و و

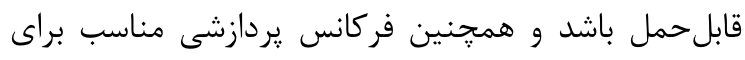

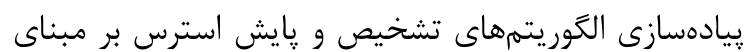
روشهاى يادگيرى ماشين و شبكههاى عصبى مصنوعى داشته

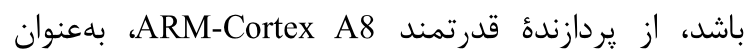

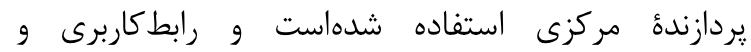

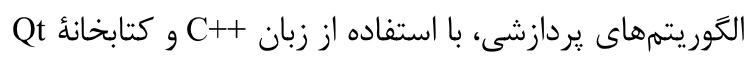
طراحى و ييادهسازى شدهاست. در ادامه، به تشريح مراحل الكوسازى و تخمين شاخص ندادي استرسى و سيس به جزئيات سختافزارى و نرمافزارى دستخاه يرداخته شدهاست.

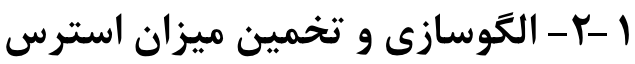
روندنماى مراحل تخمين استرس در شكل (1) نمايش داده شدهاست. منظور از تخمين استرس، ارائٔ شاخصى يُشيوسته

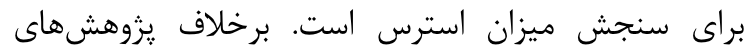
ريشين كه در آنها بهطور عمده به دستهبندى و و تفكيك سطوح استرس :رداخته شدهاست، در اين يزوهش روشى ارائه

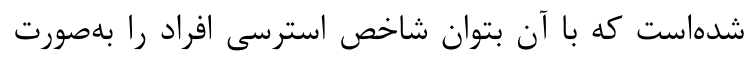

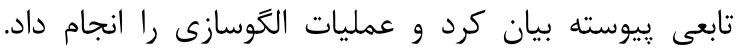
جزئيات اين روش در ادامه بررسى شدهاست.
مقاومت الكتريكى يوست كاهش و درنتيجة رسانايى الكتريكى افزايش مى يابد [35],[35]. GSR از طريق قراردادن دو الكترود بر روى سطح يوست و اعمال جريان ضعيف قابل اندازهميرى است. GSR يكى از ياسخهاى فيزيولوزيكى بدن است كه

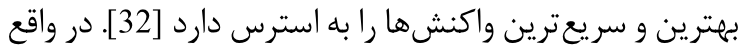

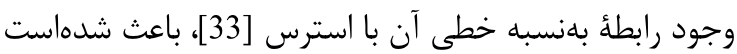

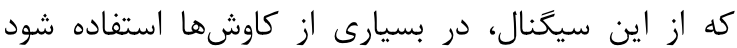

[25],[29],[33]

همانطور كه اشاره شد، استرس، يكى از عواملى است

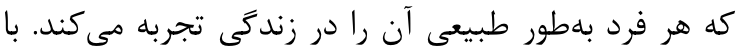

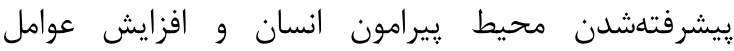
استرسزا، وجود سامانهاى كه بتواند استرس افراد ران إتشيص

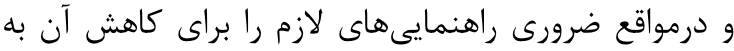

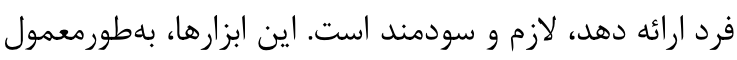
داراى حس گرهايى هستند كه شاخصههاى فيزيولوزيكى بدن

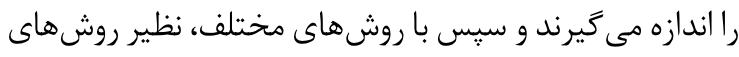

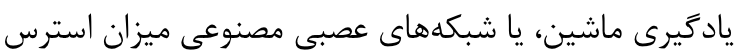

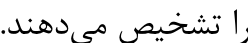
بلهور كلى، مىتوان موضوع تشخيص استرس را از دو دون رويكرد بررسى كرد. در رويكرد نخست، بسيارى از يزوهش مهنها، به طبقهبندى و تفكيك سطوح استرس به دو يا جند وضعيت

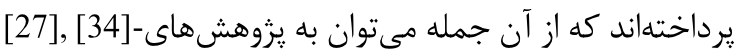

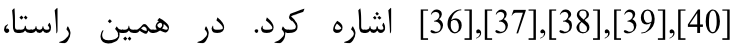

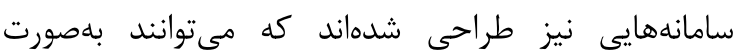
برون خط' و برخط'، سطح استرس را در افراد شناسايى كنند.

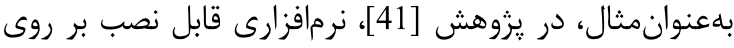
سيستمعامل اندرويد طراحى شدهاست كه مي تواند با استفاده

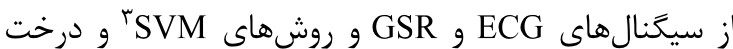
تصميم 448ل، سطوح استرس را در افراد از يكديكر تفكيك كند.

در رويكرد دوم، هدف تخمين ميزان استرس و ارائه

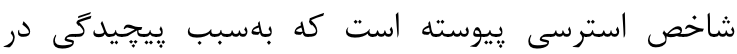

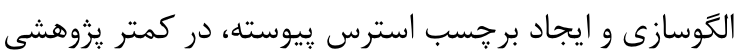

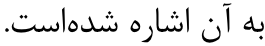

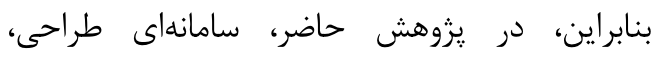
الكوسازى و ساخته شدهاست كه مىتواند با استفاده از

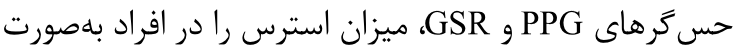

${ }^{1}$ Offline

${ }^{2}$ Online

${ }^{3}$ Support Vector Machine 
با حركت اين ينجره در بازهاى زمانى استرسى و

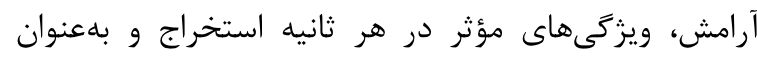
ورودىهاى الكَ در نظر كرفته مى شيود.

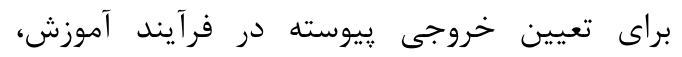

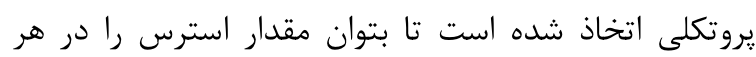

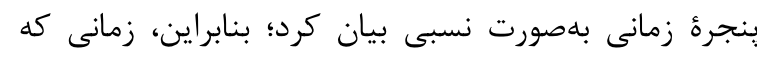

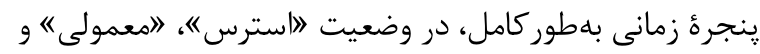

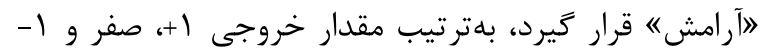

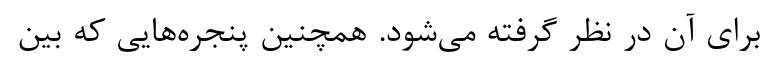

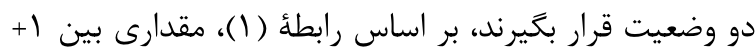

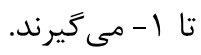

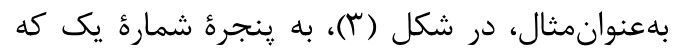

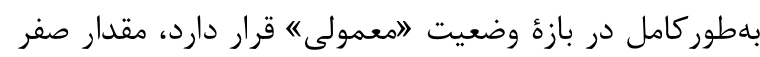

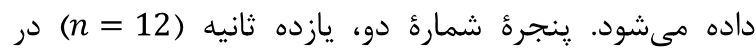

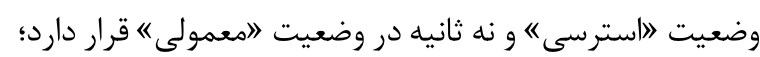

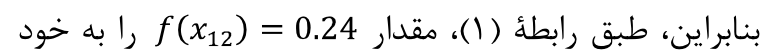

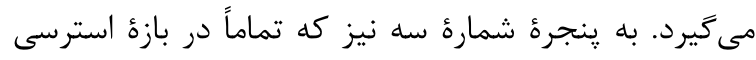

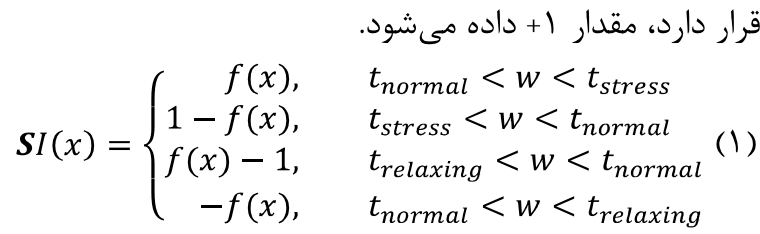

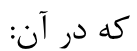

$$
f\left(x_{n}\right)=e^{\frac{-\left(x_{n}-c\right)^{2}}{2 \sigma^{2}}}, \sigma=0.3 ،=0
$$

$x_{n}=-1+0.05 \times(n-1), \quad 1 \leq n \leq 20$

در رابطههاى بالا، SI S نشاندهندة تابع استرسى، $n$

شمارة ينجره، و عبارتهاى

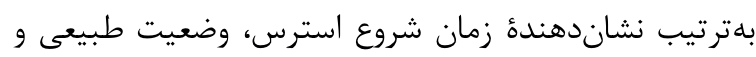

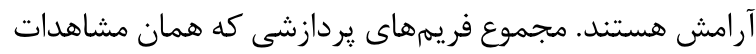

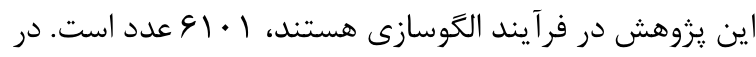

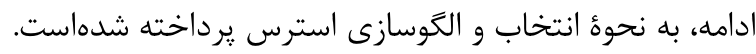

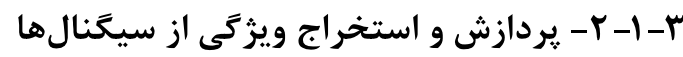

GSR سيخنال همانطور كه اشاره شد، هدايت الكتريكى يوست كه با نامهاى

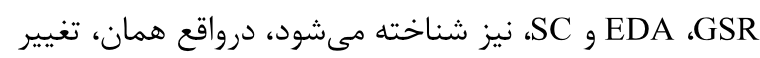

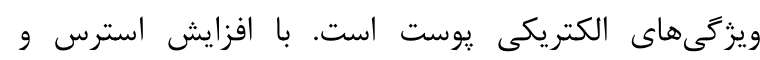

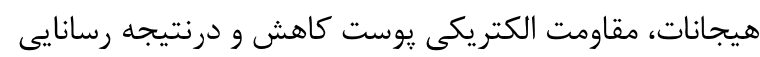

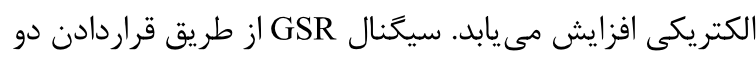

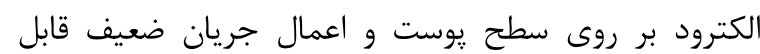

$$
\text { اندازهخيرى است. }
$$

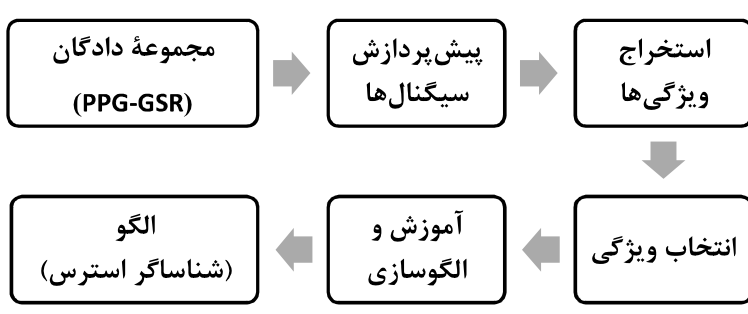

(شكل -) ): روندنماى تشخيص استرس

(Figure-1): Stress detection diagram

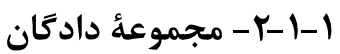

يايخاه داده استفادهشه در اين يزوهش، حاصل يزوهشهاى

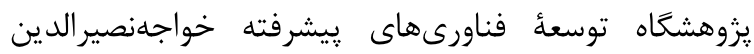
طوسى [42] و شامل ده ثبت استرسى است كه متخصصان،

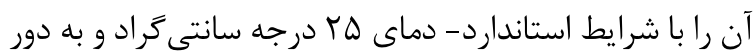
از آلودكى صوتى و تصويرى- ثبت كردهاند. عوامل ايجاد آرامش و استرس در هر ثبت، در جدول (1) ذكر شدهاست.

(جدول-1): دادههاى ثبتشده بههمراه توضيح عوامل استرسزا

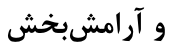

\begin{tabular}{|c|c|c|}
\hline 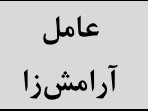 & عامل استرسزا & رديف \\
\hline فكركردن به & فكركردن به عوامل استرسزا & 1 \\
\hline صداى دريا & فكر كردن به فردى كه خاطره بدى از او دارد & r \\
\hline صداى دريا & نمنزجنكنى از كشتن يك فرد با تبر: & $r$ \\
\hline صداى دريا & نماهنكى از تعقيب و كريز & r \\
\hline صداى دريا & نماهنكى از تعقيب و كريز و يرتاب از هواييما & $\Delta$ \\
\hline صداى دريا & نماهنكى از تعقيب و كريز & 4 \\
\hline صداى دريا & نماهنكى تخيلى از تعقيب و كريز & $\mathrm{v}$ \\
\hline صداى دريا & نماهنگ كشتن يك فرد توسط خودش & $\Lambda$ \\
\hline صداى دريا & نماهنگ كشتن يك فرد توسط خودش & 9 \\
\hline صداى دريا & نماهنگ تعقيب و كريز & 1. \\
\hline
\end{tabular}

(Table-1): Recorded data and their stress and relaxation related explanations

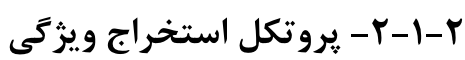

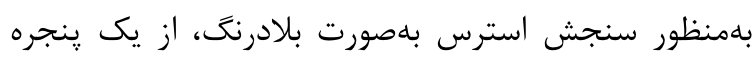

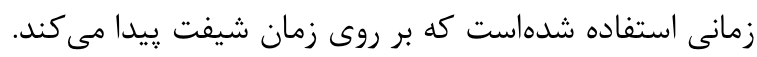

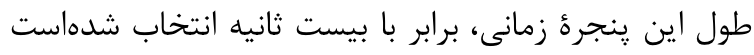

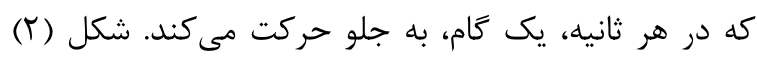

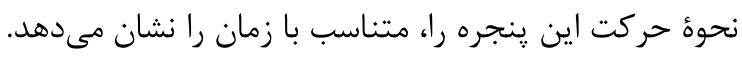




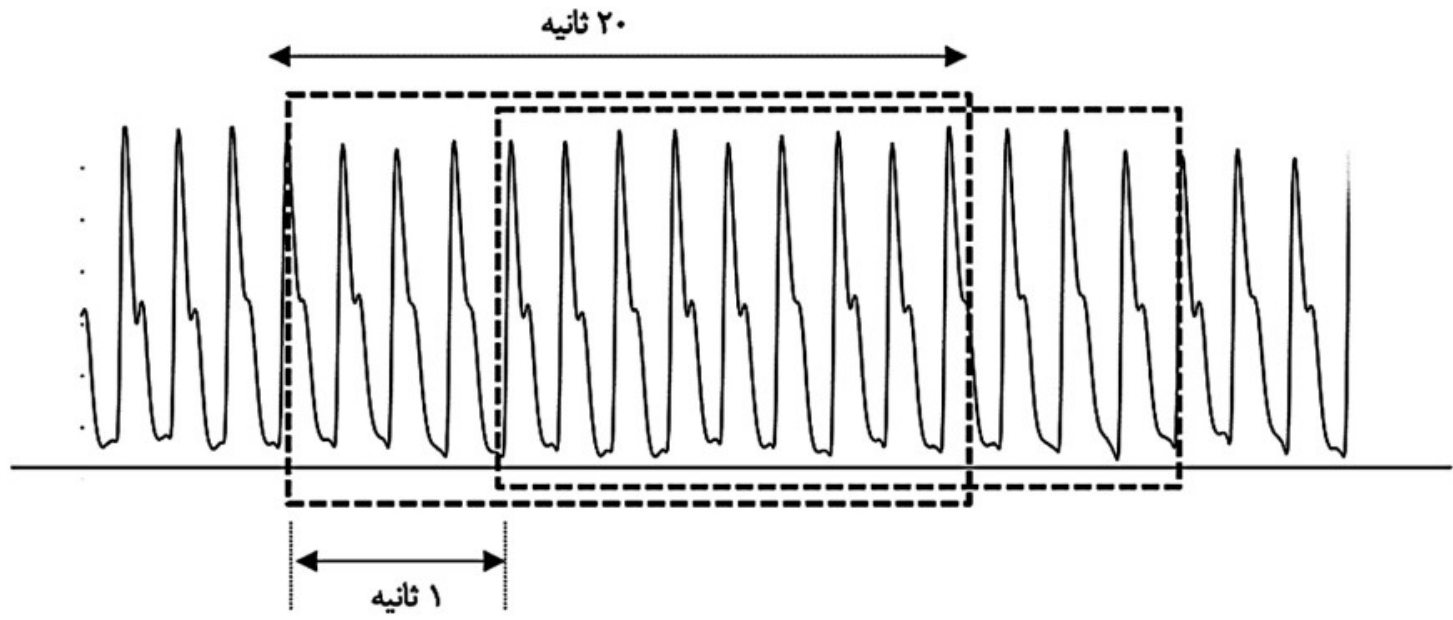

(شكل -r): ينجرة زمانى مورد استفاده براى تحليل سيگنال بهصورت برخط :

(Figure-2): Required time windows to online signal analysis
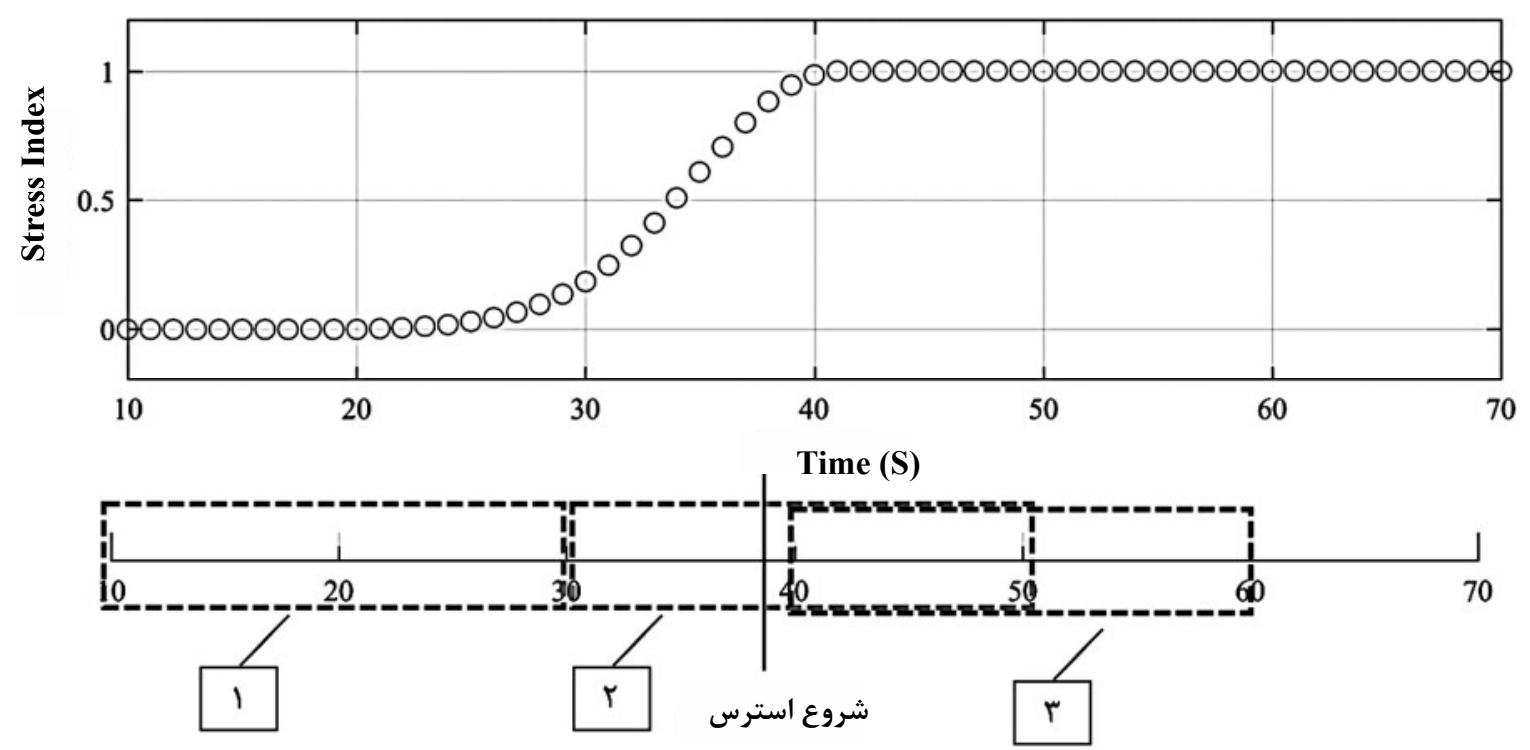

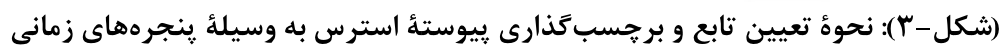

(Figure-3): Continuous labeling of the stress via time windows

ويزگ

GSR استخراج مىشوند، عبارتاند از: ميانگين سيخنال GSR

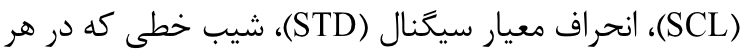
ينجره به سيخَنال برازش مىشود (Slope)، ميانگين دامنهُ ياسخهاى رسانايى (MeanAmplitude) و ميانگين زمان بين شروع تا يايان هر ياسخ كه به زمان صعود معروف است ( Mean .(Rise Time

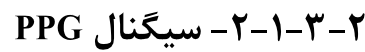
امروزه، تغييرات نرخ ضربان قلب (HRV) كه درواقع همان نوسانهاى نرخ ضربان گره سينوسى است، ابزار بسيار مهرى
ييش از استخراج ويثزَى، ابتدا بر روى اين سيخنال،

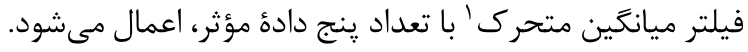

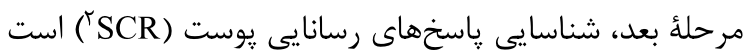
كه توسط الكوريتمى كه در [43] ارائه شدهاست، انجام مىيذيرد. عملكرد الكوريتم بالا به اين صورت است كه نخست، با استفاده از مشتق نخست، نقاط كمينأ محلى شناسايى و وند سيس نزديكترين بيشينه نسبت به هر كمينهُ محلى انتخاب

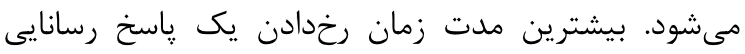

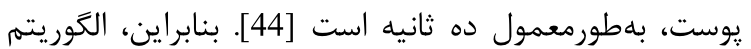
تنها ده ثانيه به دنبال يِيك بعد از شروع پِاسخ يوست ميىشود.

\footnotetext{
${ }^{1}$ Moving Average

${ }^{2}$ Skin Conductance Response
} 
جهت كمركردن وابستكى الكوسازى به تغييرات بين افراد،

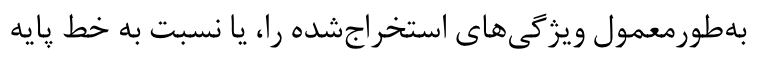

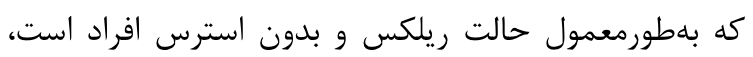

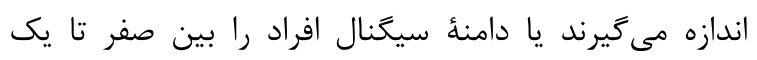

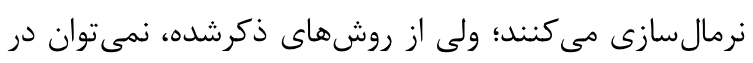

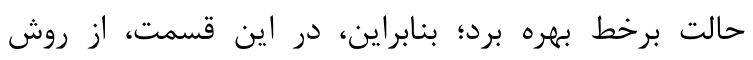

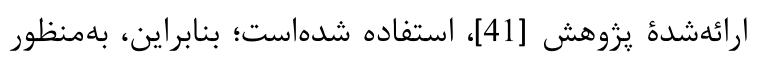

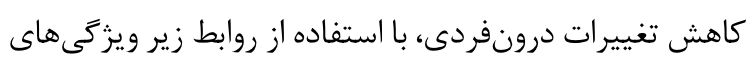

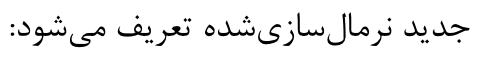

$$
\operatorname{CoV}(S C)=\frac{S T D}{M e a n S C L}
$$

MeanAmplNorm $=\frac{\text { MeanAmplitude }}{\text { MeanSCL }}$

$$
\operatorname{CoV}(N N)=\frac{S D N N}{M e a n I B I}
$$

$$
\text { RMSSDNorm }=\frac{R M S S D}{\text { MeanIBI }}
$$

لازم به ذكر است كه تعداد يِيكها، Mean Rise Time،

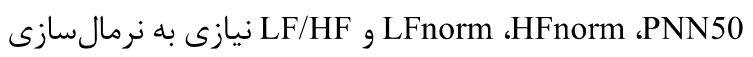
ندارند [50]. همجنين، نتايج الكوسازى يس از إز اعمال

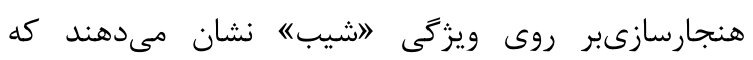

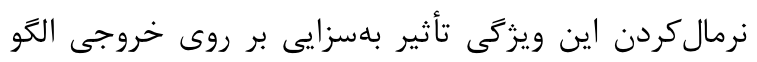

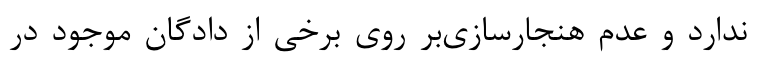

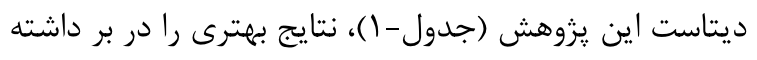

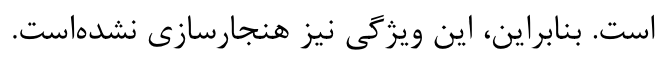

\section{هـ - ا- r- انتخاب ويزَّى هاى بهينه}

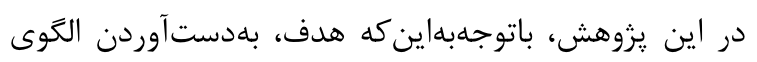

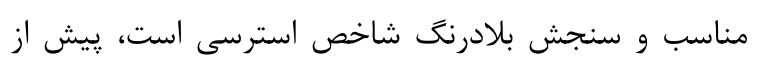

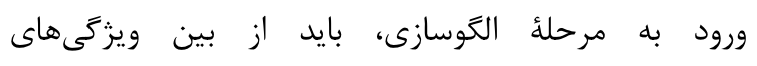

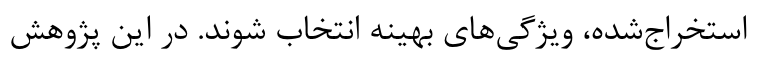

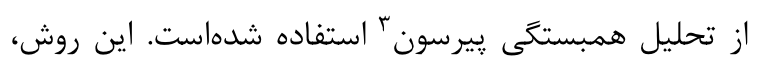

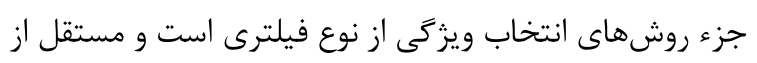

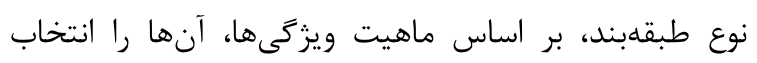

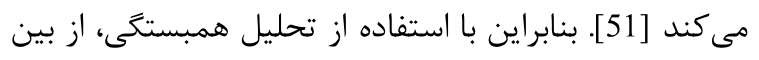

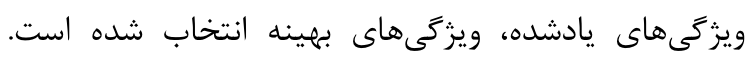

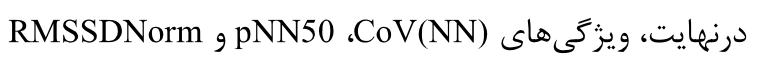

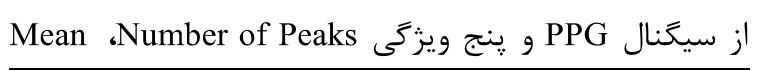

${ }^{3}$ Pearson
براى تحليل سيستم قلبى -عروقى و همجنين، دستخاه اعصاب

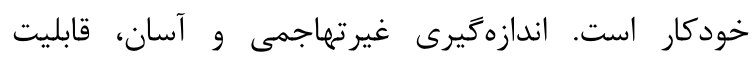

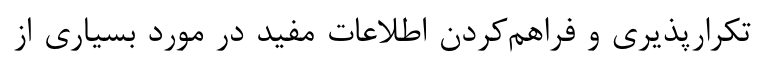

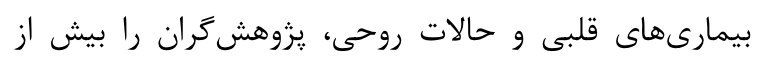

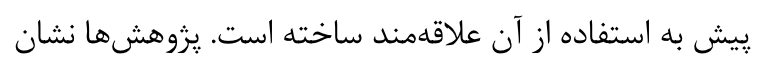

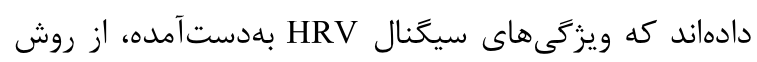

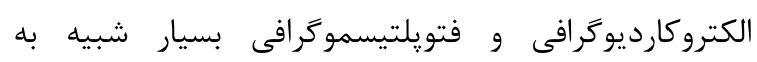

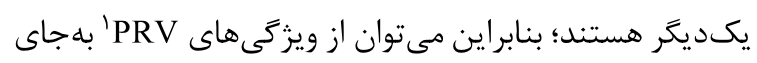

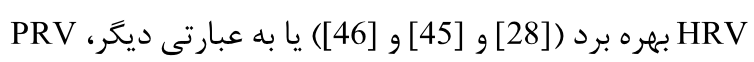

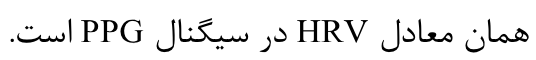

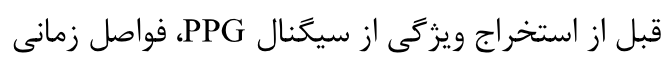
بين هر يالس (IBI) توسط روش ارائهشده در [47) تصحيح

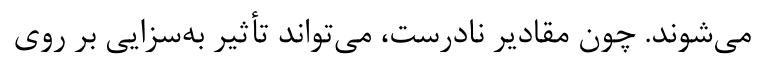

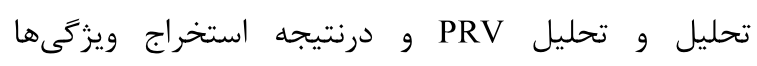
داشتهباشد [48]. در اين روش، اختلاف بين هر مقدار

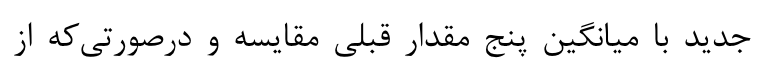

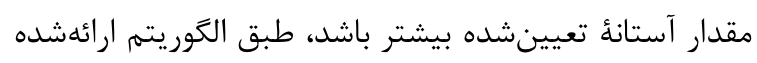

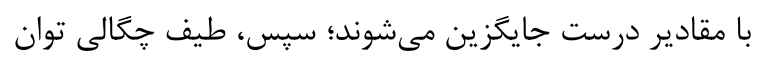

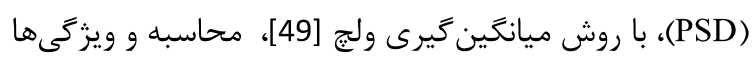

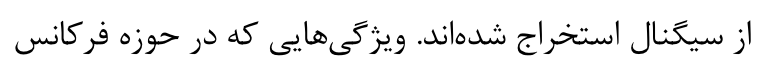

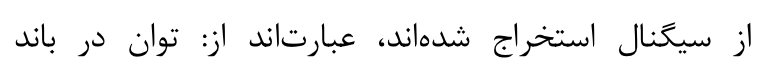

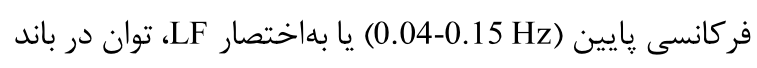

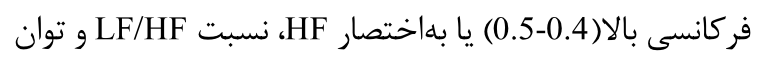

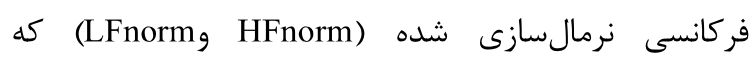

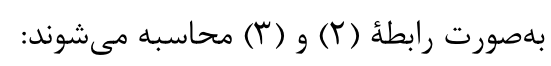

$$
\begin{aligned}
& \text { LFnorm }=\frac{L F}{L F+H F} \\
& \text { HFnorm }=\frac{H F}{L F+H F}
\end{aligned}
$$

همجِنين ويزگى هاى استخراجشده در حوزه زمان

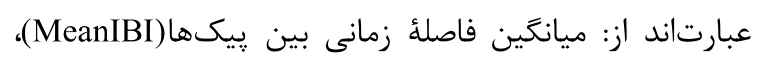

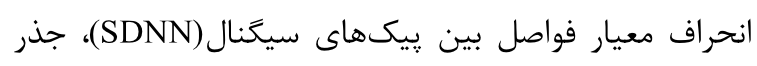

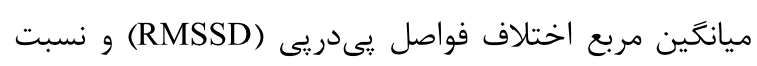

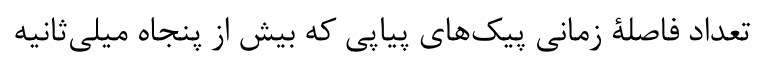
هستند، به تعداد كل بيكها (pNN50).

\section{ت}

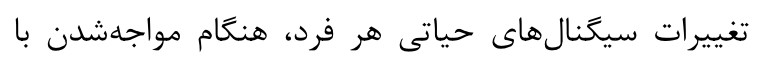

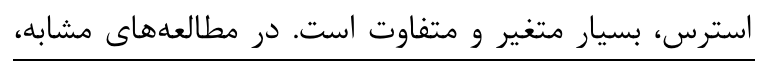

\footnotetext{
${ }^{1}$ Pulse Rate Variability

${ }^{2}$ Inter Beat Interval
} 
ينجرهزذارى بر روى سيگنال، به دست آمدهاست. از مجموع

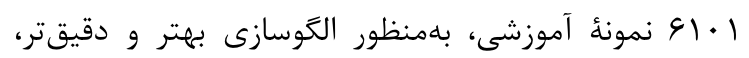
| I9VI نمونه براى الكوسازى انتخاب شدهاست. انتخاب اين نمونهها به اين علت بودهاست كه با توجه به مجموعة دأه دادكانِ

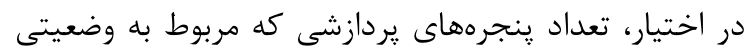

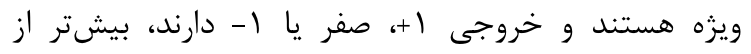
ينجرههايى است كه مقادير فازى دارند. بنابراين، بهمنظور

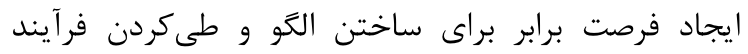

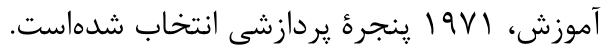

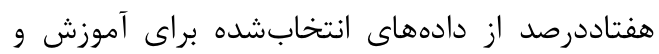
سىدرصد براى آزمايش بهصورت اتفاقى از مجموعهُ دادئان إنان

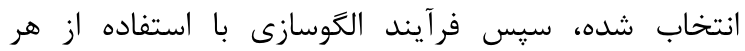

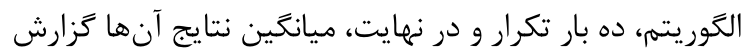
شدهاست. در شكل (\&) تابع استرسى هدف نشان دان دادئ

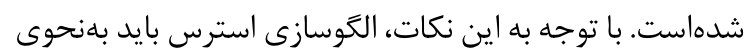

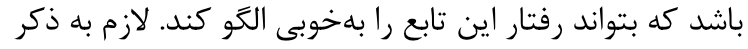

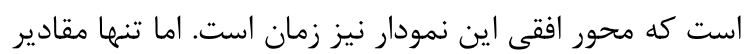
درست را دربرمى گيرد. بلعنوانمثال، مقدارى كه اين تابع در

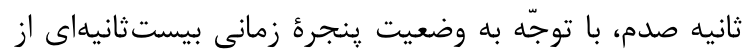

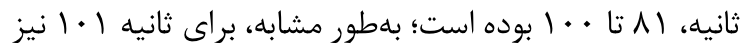

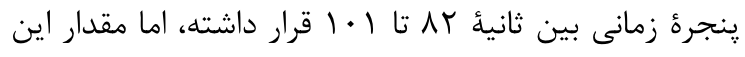
تابع در ثانيه ه/ • • ا تعريف نشدهاست.
ز MeanAmplNorm ، Slope ،Rise Time سيخنال GSR انتخاب شدهاند.

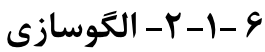
الكَوسازى استرس، به اين مفهوم است كه يس از كذشت

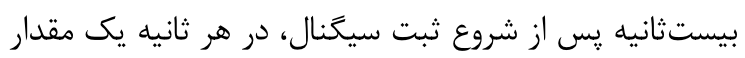
براى استرس تخمين زدهود. بهاينمنظور، در اين يزوهش از شبكؤ عصبى مصنوعى MLP، فازى-عصبى تطبيقى (ANFIS) استفاده و نتايج آنها با يكديكر مقايسه شده است. ساختار شبكأ MLP بلنحوى است كه مىتوان از تنظيمات مختلفى جهت تنظيم الكوريتم و شاخصههاى يادكيرى استفاده كرد.

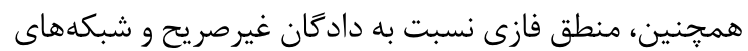
عصبى نسبت به دادكان نويزى تحمليذيرى بالايى دارند.

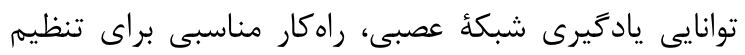

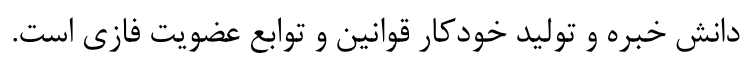
از سوى ديخر منطق فازى امكان گسترش توانايى برونيابى

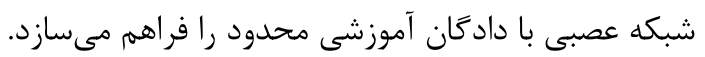
در اين نوع الكَوسازى، هدف، تخمين مقدارى بِيوسته براى استرس بر اساس سيخنالهاى حياتى افراد است. بنابراين،

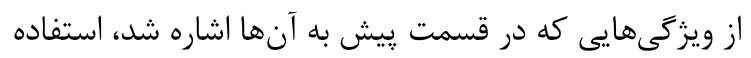

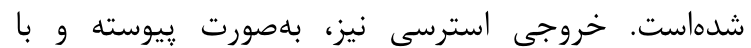

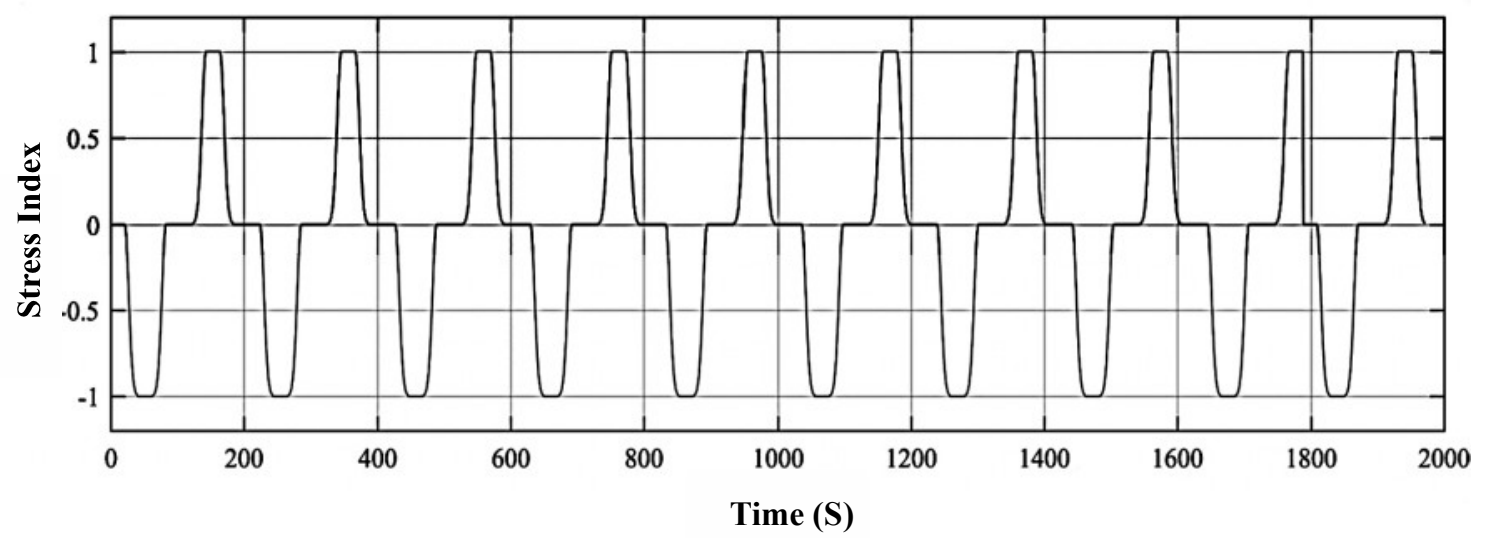

(شكل - (\$): خروجى ييوستة استرس :

(Figure-4): Continuous stress output

سامانهُ يردازش اطلاعات است. اين سامانه از شمار زيادى

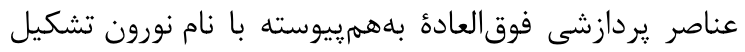

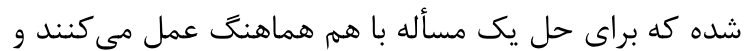
با سينايسها (ارتباطات الكترومغناطيسى) اطلاعات را منتقل

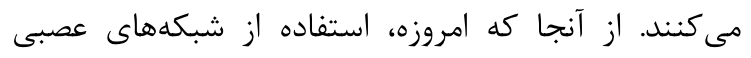
مصنوعى در بسيارى از يزوهشها رايج و متداول شده، از ذكر أركا جزئيات مربوط به معرفى لايهها، توابع فعالسازى، نحوة
شبكهاى عصبى مصنوعى' روشهاى محاسباتى

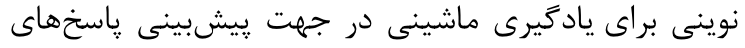

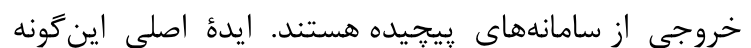

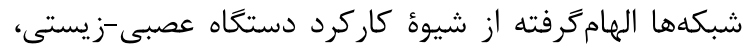

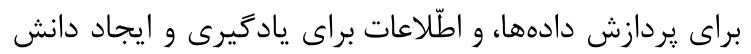
است. عنصر كليدى اين ايده، ايجاد ساختارهايى جديد براي براى

${ }^{1}$ Artificial Neural Network (ANN) 
r-צ-1-Y - الكوسازى با استفاده از شبكئ فازى-عصبى تطبيقى

سامانهاى فازى براى نخستينبار توسط بروفسور لطفىزاده

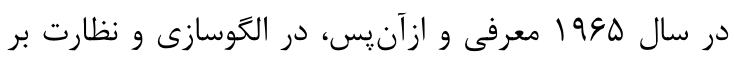

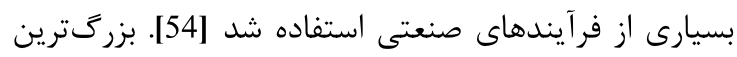

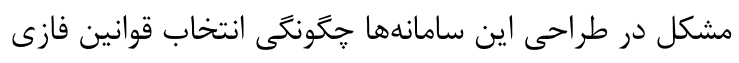

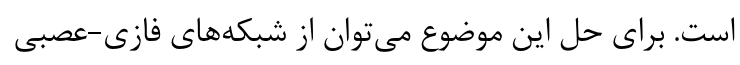

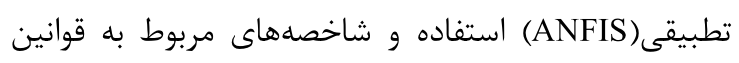

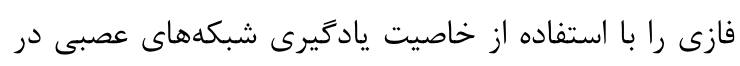

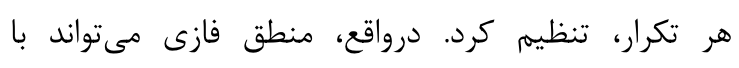

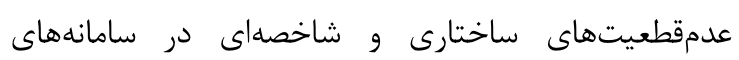
غيرخطى مقابله كند.

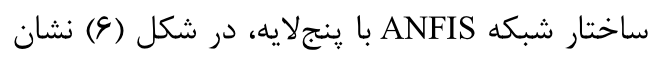

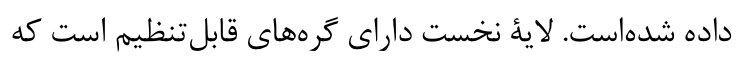

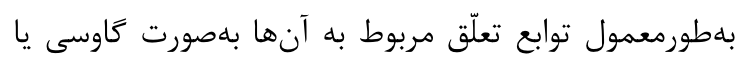

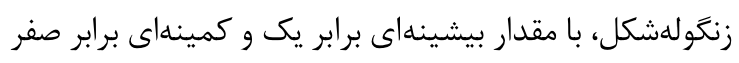

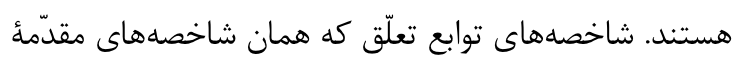

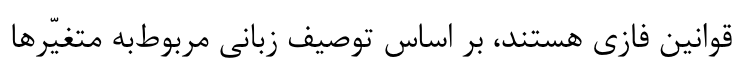

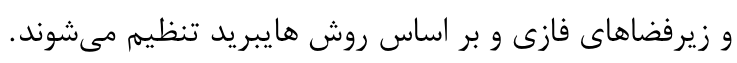

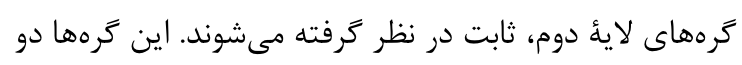

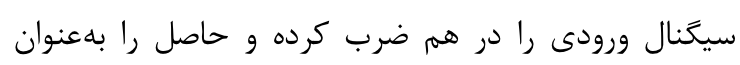

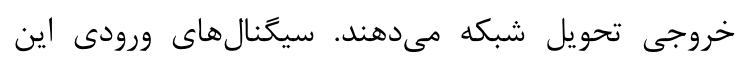

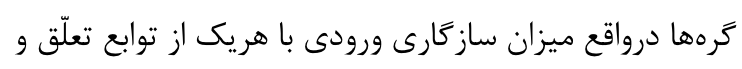

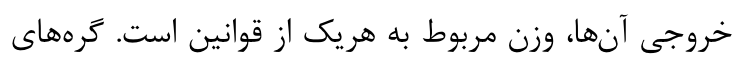

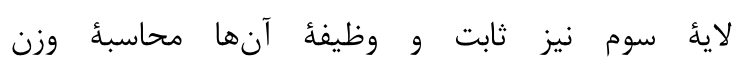

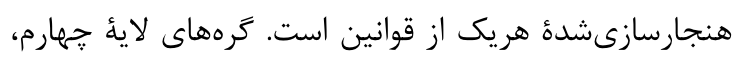

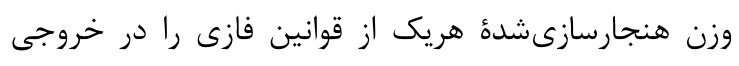

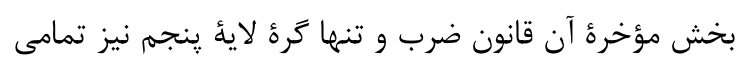

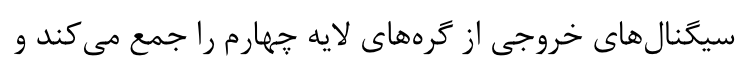

بلهنوان خروجى شبكه تحويل مى دهد [55 الايه

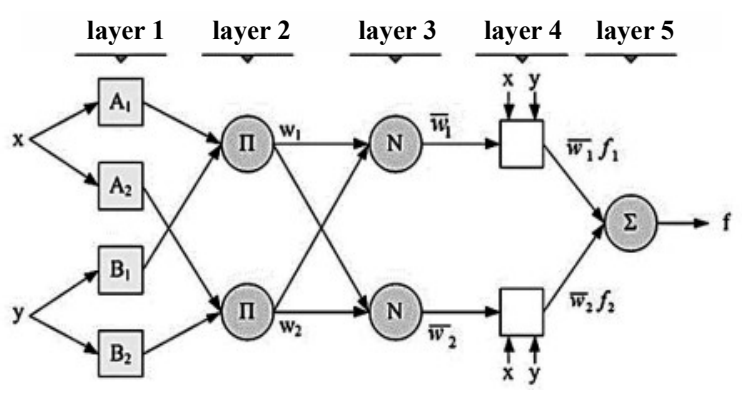

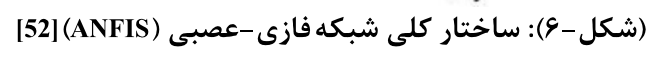

(Figure-6): General structure of the ANFIS
بلدروزرسانى وزنها و ...، يرهيز شده و در ادامئ تنها به معرفى

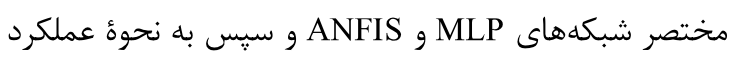
و ذكر شاخصههاى آنها يرداخته شدهاست.

MLP 1-9-1-

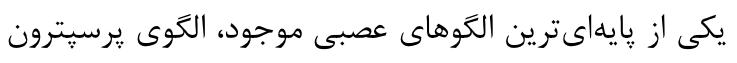

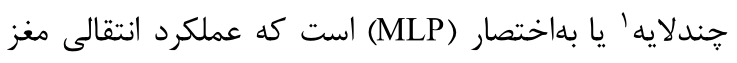

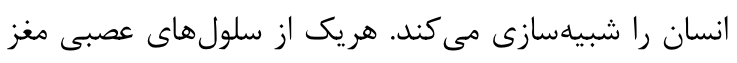

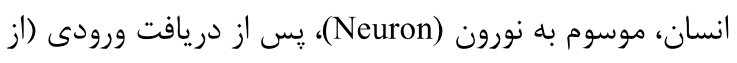
يكى سلول عصبى يا غيرعصبى ديكر)، بردازشى روى بـ آن آن انجام و نتيجه را به يك سلول ديكر (عصبى يا غيرعصبى) انتقال

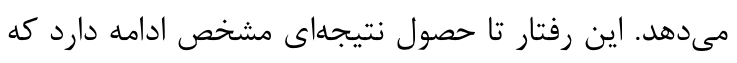

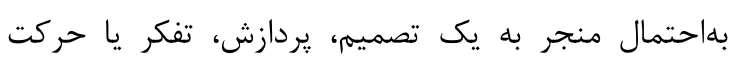
خواهدشد. شبكه MLP مجموعهاى از نورونهاى پايه است كه در

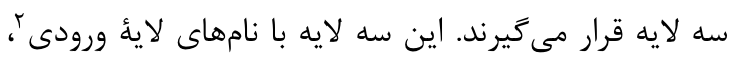

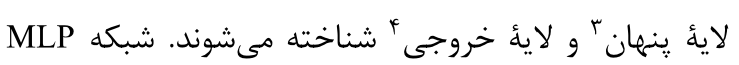

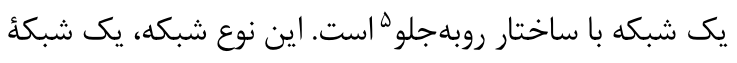

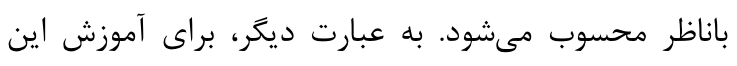

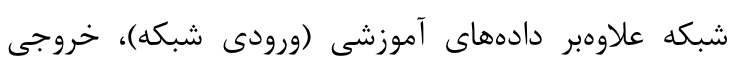

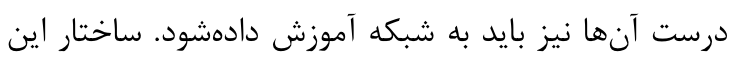
نوع شبكه در شكل (ل) نشان داده شدهاست.

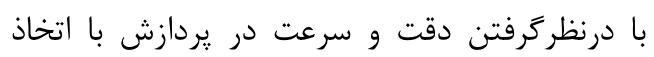

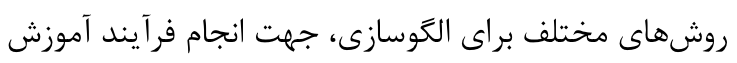

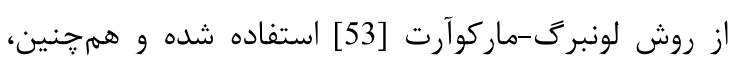

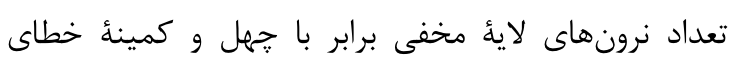

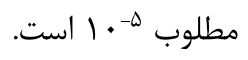

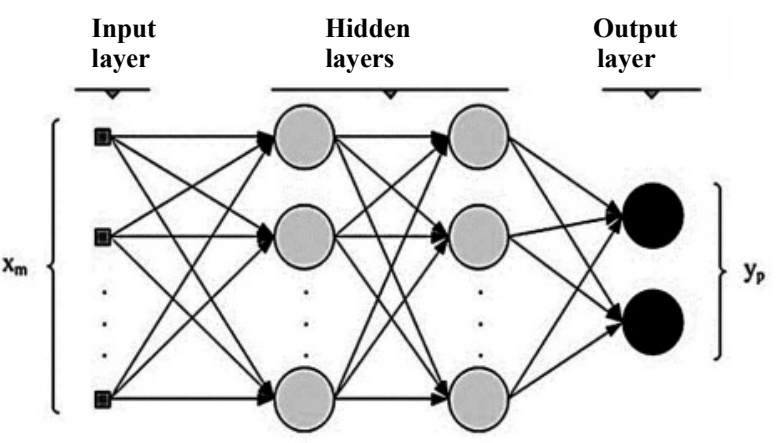

[52] MLP شكل - (ه) : ساختار كلى شبكهعصبى

(Figure-5): General structure of the ANN

\footnotetext{
${ }^{1}$ Multi-Layer Perceptron

${ }^{2}$ Input Layer

${ }^{3}$ Hidden Layer

${ }^{4}$ Output Layer

${ }^{5}$ Feed Forward
} 


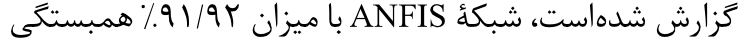
با خروجى حقيقى، ميانگين خطاى V V • • • و انحراف معيار

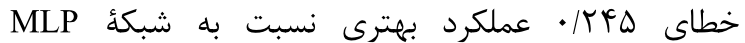

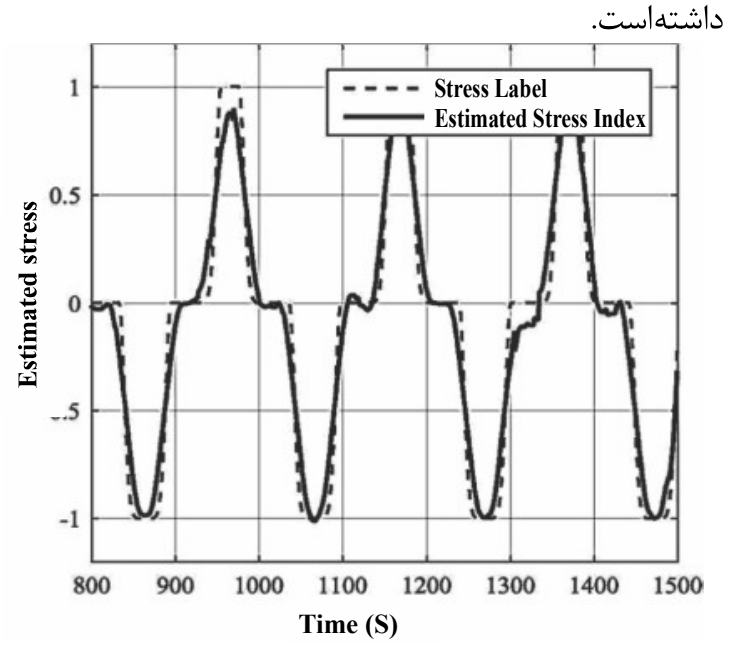

(شكل - (^): نتايج تخمين استرس با استفاده از ANFIS بر روى

دادههاى آموزش و آزمون

(Figure- 8): Stress estimation results using ANFIS for the train and test data

(جدول ץ): ميانگين نتايج الكَوسازى براى ده بار تكرار

(Table- 2): Average results of modeling for 10 iteration of the stress detection algorithms

\begin{tabular}{|c|c|c|c|c|}
\hline 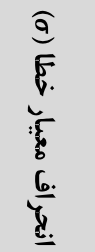 & 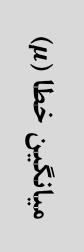 & 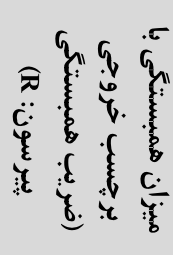 & 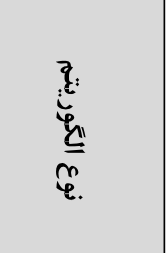 & $\underbrace{c}_{c}$ \\
\hline 0.2910 & 0.078 & $83.63 \%$ & $\begin{array}{c}\text { شLP } \\
\text { MLبك }\end{array}$ & 1 \\
\hline 0.245 & $\mathbf{0 . 0 0 7}$ & $91.92 \%$ & ANFIS & $r$ \\
\hline
\end{tabular}

r-r-r - طراحى و ساخت دستگًاه

در اين قسمت، به تشريح مراحل طرّاحى و و ساخت سختافزارى و نرمافزارى سامانه قابل حمل سنجش و و يايش

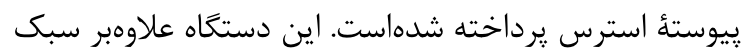

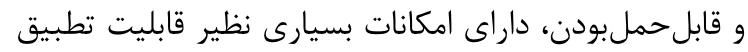

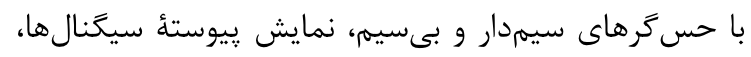

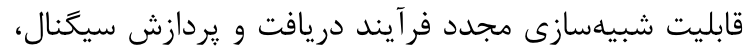
ضبط و و يخش صدا، ذخيره اطلاعات شخصى افراد، امكان

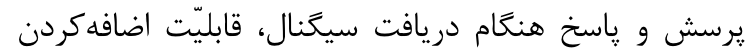

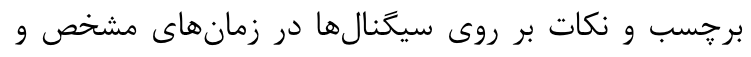
بسيارى از موارد ديخر، است. هدف از ساخت اين دستخاه نيز
يكى از نكات بسيار مهرم در طراحى سامانههاى فازى،

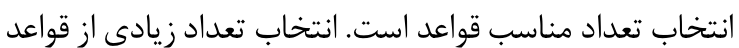
باعث بيجِيدهشدن سامانه مىشود و انتخاب تعداد كمى از

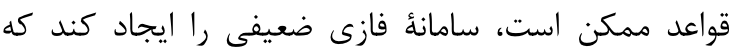

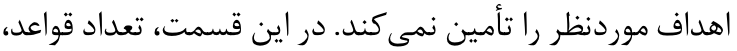
بهعنوان يك شاخصة مهم در سامانهاى فازى در نظر كرفتهشده و بر اساس زوجهاى ورودى-خروجى و خطاى نهاى الكوسازى، تعيين مىشود. علت اصلى خوشابندى، گروهبندى زوجهاى ورودى-خروجى در دستههاى مختلف و استفاده از

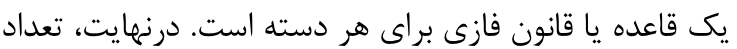

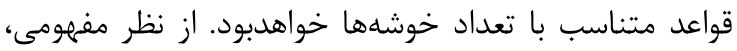

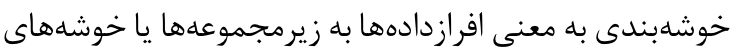

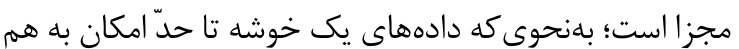

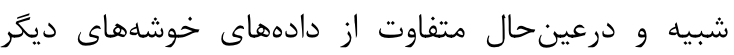
باشند[56] در اين :رثوهش، با توجّه به اهميت دقّت و سرعت

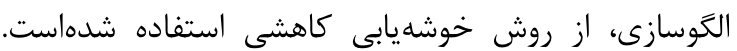

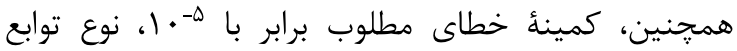

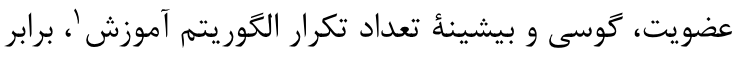

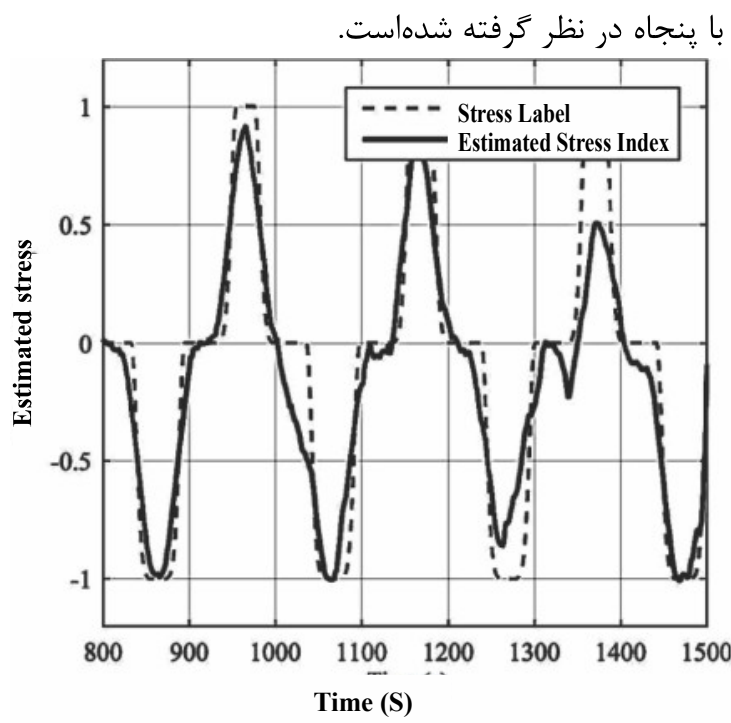

(شكل-YV): نتيجة تخمين استرس با استفاده از شبكةٔ عصبى

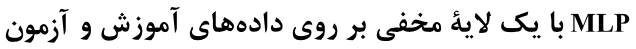

(Figure-7): Stress estimation results using MLP with one hidden layer for the train and test data

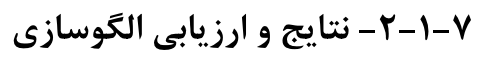

در جدول (r) ميانگين نتايج دهبار تكرار، براى الگوريتمهاى إلى الكوسازى استرس ذكر شدهاست. همانطوركه واضح است، با دهاب توجه به شكل (V)، شكل (N) و نتايجى كه در جدول ${ }^{1}$ Epoch 


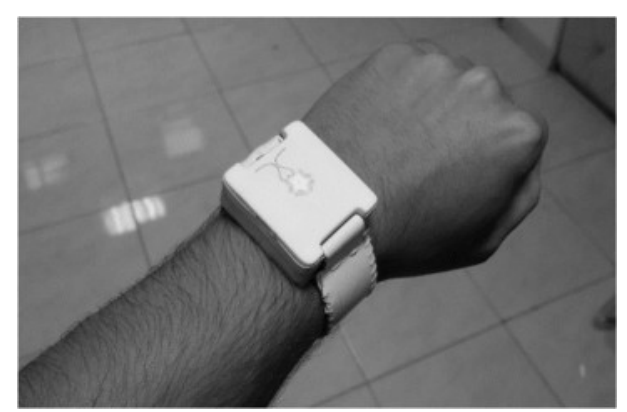

(شكل -1(): سامانهُ اخذ سيكنالهاى فيزيولوزيكى (بلون

بدون سيم (بلوتوث)

(Figure-11): Wireless sensor system (Bluetooth)

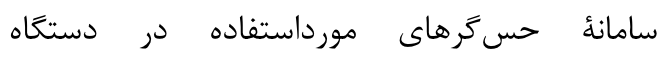

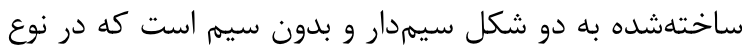

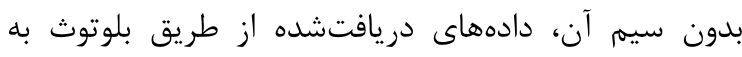

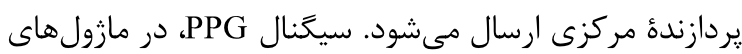

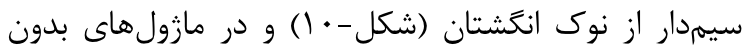

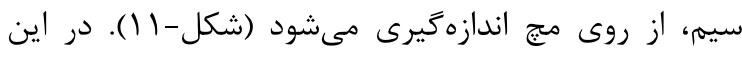

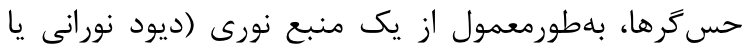

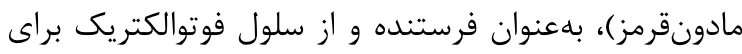
تبديل نور عبورى به سيخنال الكتريكى استفاده مى شود.

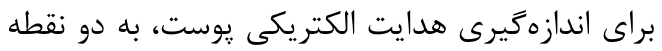

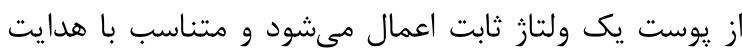

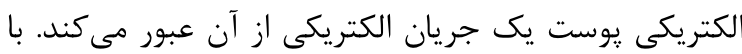

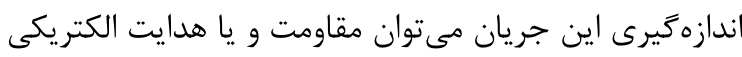

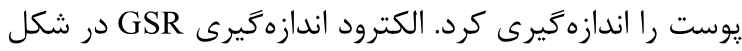

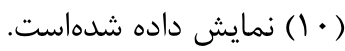

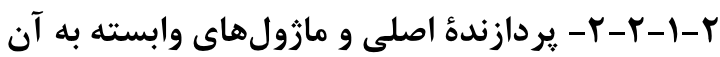
امروزه بيدايش هستههاى بردازشى ب ب بيتى مانند ARM،

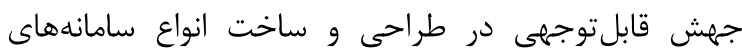

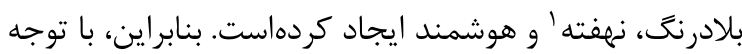

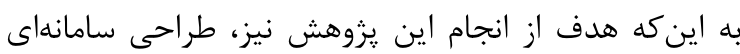

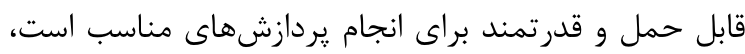

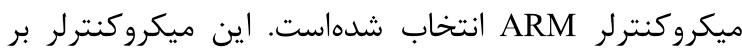

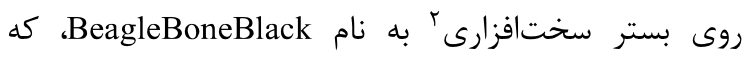

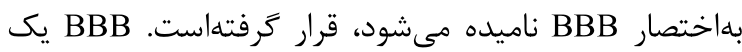

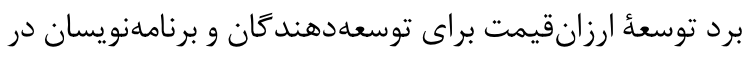

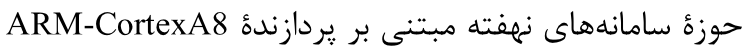

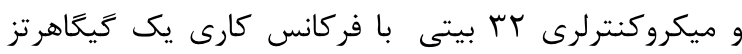

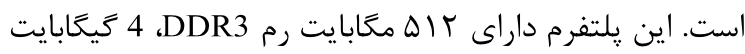

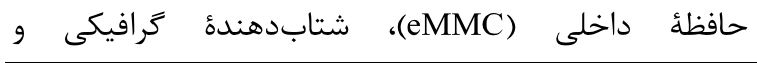
${ }^{1}$ Embedded

${ }^{2}$ Plattform
ايجاد يلتفرمى جهت پِيادهسازى الكوريتمهاى تشخيص و پايش استرس بر مبناى روشهاى يادكيرى ماشين و شبكههاى

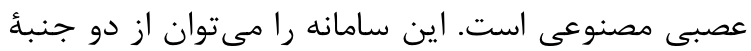
سختافزارى و نرم|فزارى بررسى كرد.

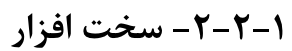

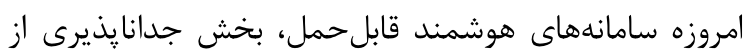

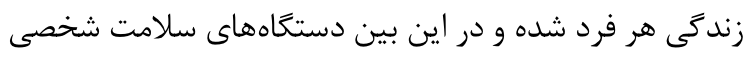

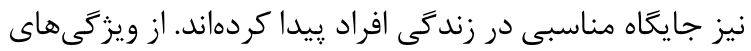

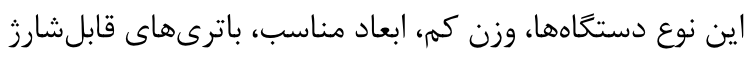

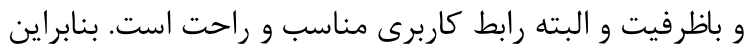

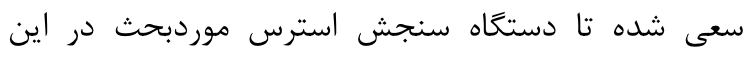

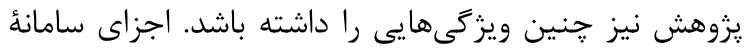
موردنظر در شكل (9) نشان داده شدهاست.

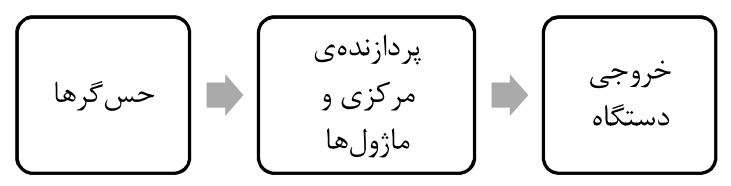

(شكل-9): بخشهاى مختلف سختافزارى دستخاه

(Figure-9): Hardware parts of the system

همانطور كه در شكل (9) مشاهده مى كنيد، اين سامانه داراى سه بخش اصلى شامل حسكرها، يردازندأ مركزى و و

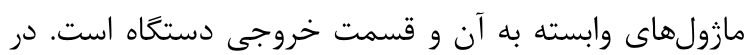
ادامه، به تشريح اين سه بخش بردائه بـ فاخته شدهاست.

$$
\text { إ }
$$

بلمنظور دريافت سيخنالهاى PPG و

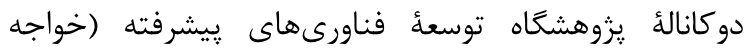

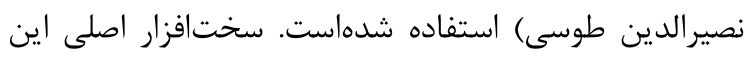

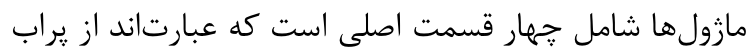

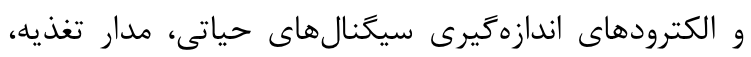

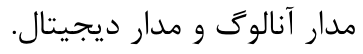

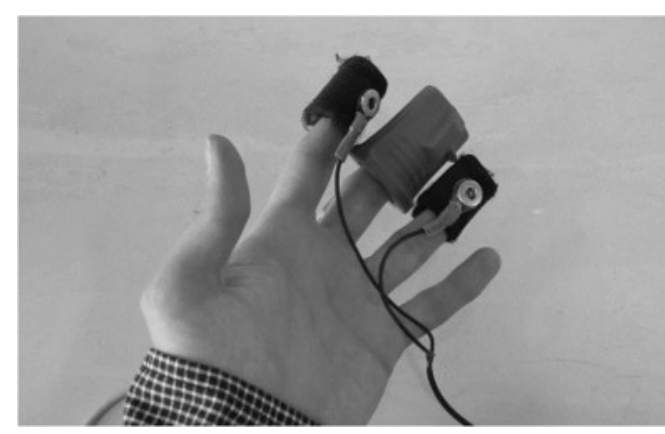

(شكل -+1): نحوء اتصال حس گَرها به انغَشتان، در سامانئ

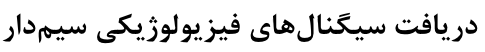
(Figure-10): Wired sensor connection method 
سريال است. RFCOMM لايههاى پايينى يروتكل bluetooth را به لائ L2CAP متصل مىكند. وظيفه ايجاد ارتباط RFCOMM

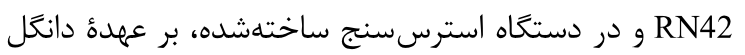
بلوتوث ورثن سه است كه در شكل (ها ) نشان داده شدهاست.

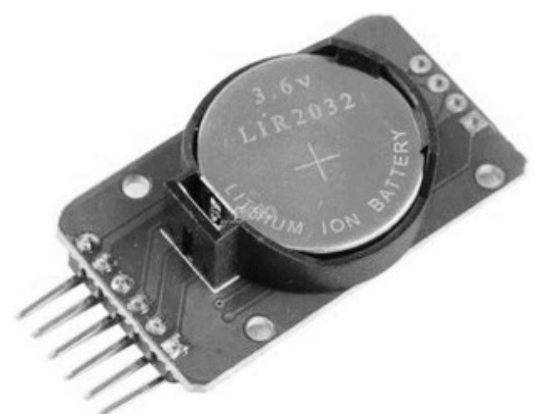

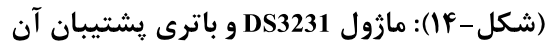
(Figure-14): DS3231 module and backup battery

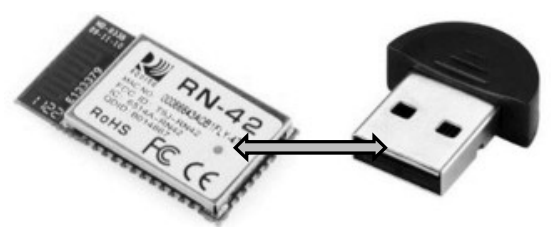

(شكل - (1): فرستنده و كيرندهاى بلوتوث

(Figure-15): Bluetooth transmitter and receiver module

براى فراهمآوردن امكان نمايش رابط كاربرى و صفحة

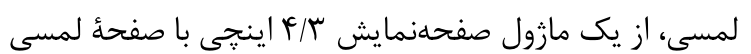
مقاومتى استفاده شدهاست. اين صفحهنمايش، داراى وضى وضوح

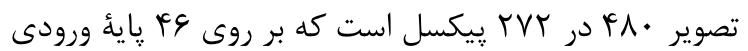
و خروجى برد قرار مى گيرد و در شكل (ع) نشان ندان داده

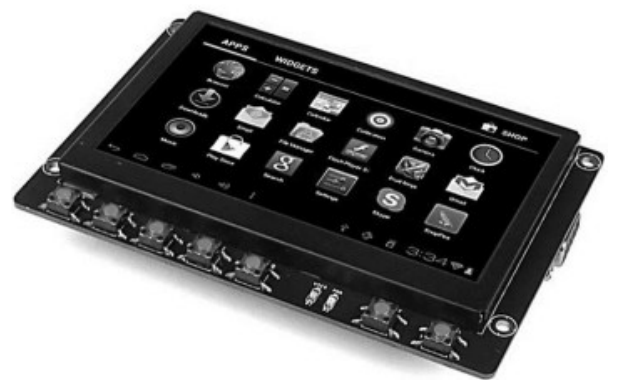

(شكل-81): مازول نمايشكر CS-BBB-EXP43

(Figure-16): CS-BBB-EXP43 monitor module

r-r-r-r - نرمافزار و رابط كاربرى

يكى از مسائلى كه موجب ايجاد سهولت در استفاده از يكى

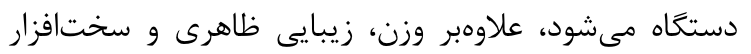
مناسب آن، مساله رابط كاربرى دستًاه است. در طراحى رابط
شتابدهندة مميّز شناور NEON است؛ همجنين، اين يلتفرم

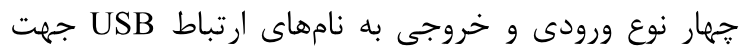

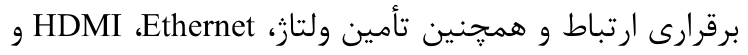

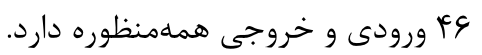
بهمنظور تأمين انرزى دستكاه، از باترى ليتيوم-يليمر

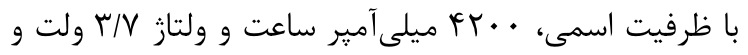
بلمنظور فراهمآوردن ولتاز مناسب كارى دستخاه از يك مبدل أفزاينده يا Boost Converter، بر وائائ آىسى ركولاتور MAX756 استفاده شدهاست. اين مبدل افزاينده كه در (شكل-r| (r) نشان داده شدهاست، در ورودى خود

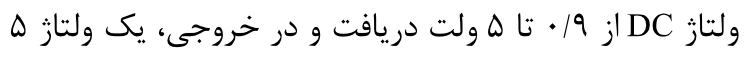
ولت ركولهشده و ثابت ايجاد مى كند.

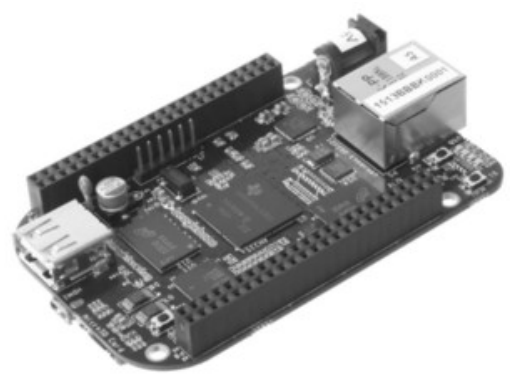

(شكل-reagleBoneBlack (I) برد توسعة

(Figure-12): BeagleBoneBlack evaluation board

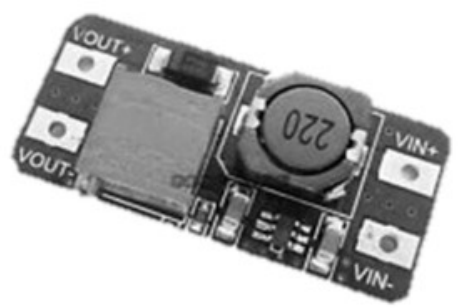

(شكل - r): مازول مبدل ولتاز

(Figure-13): Voltage convertor module

بلهور معمول، در رايانها يا سامانههاى قابل حمل زمان

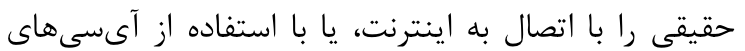

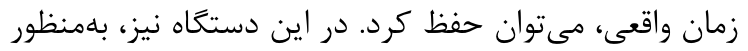

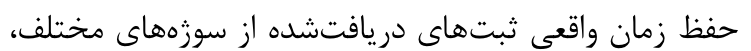

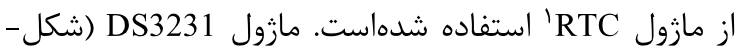

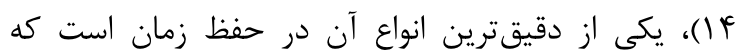

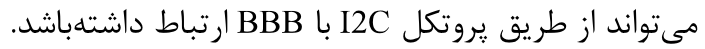

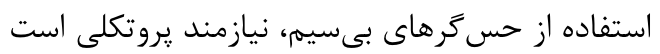

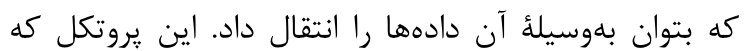
نام دارد، تنظيمات كابلى RFCOMM بدون سيم شبيهسازى مى كند و مناسب براى انتقال دادههاى نائ

${ }^{1}$ Real-time clock 
سؤالات و يخش صداى ذخيرهشده هنگام مصاحبه است

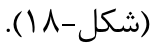

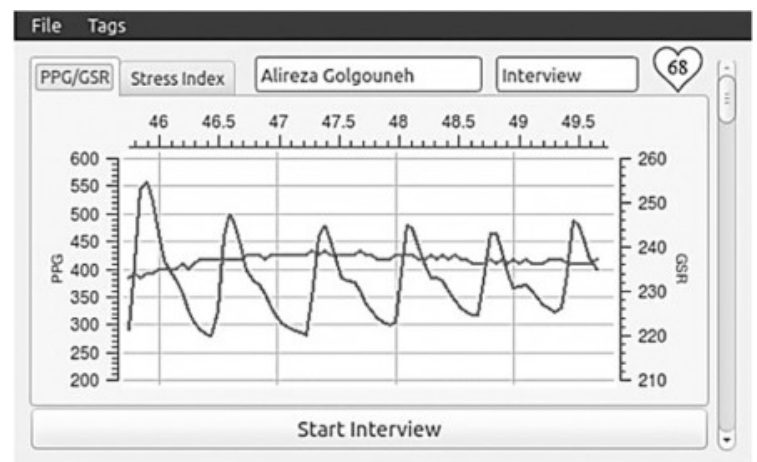

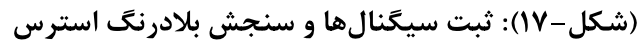

(Figure-17): Signal recording and real-time stress measurement

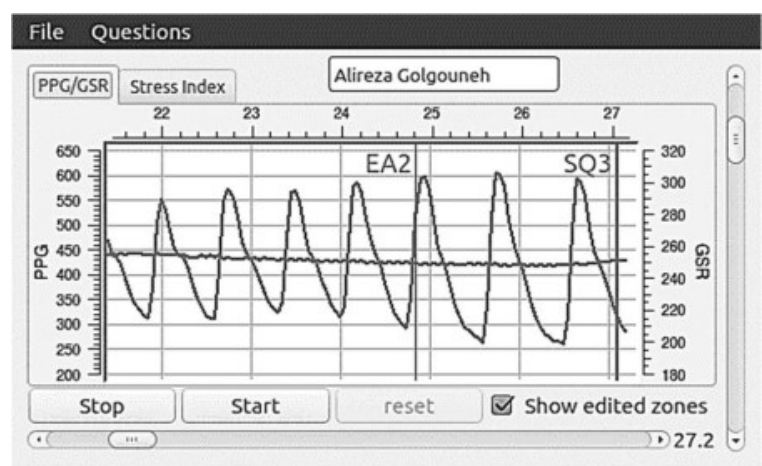

(شكل -1)(1): فرم شبيهسازى مجدد مصاحبه

(Figure-18): Simulation of the recorded interview r-r-r-r-r-rازنگرى اطلاعات و سيگنالها در حالت آفلاين

يكى ديخر از بخشهاى اين رابط كاربرى مشاهدء آفلاين سيخنالها و ويرايش بخشى از سيگنالهاست. بدين منظور،

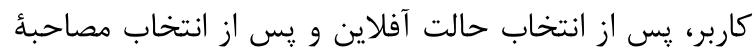

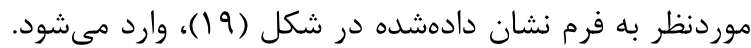

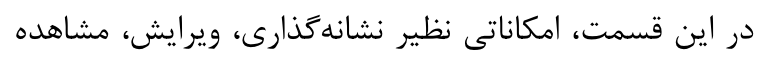
و بررسى دقيقتر قسمتى از سيگنال و غيره وجود دارد كه مىتوان در مورد ثبتهاى دريافتى اين امكانات را به كار بست.

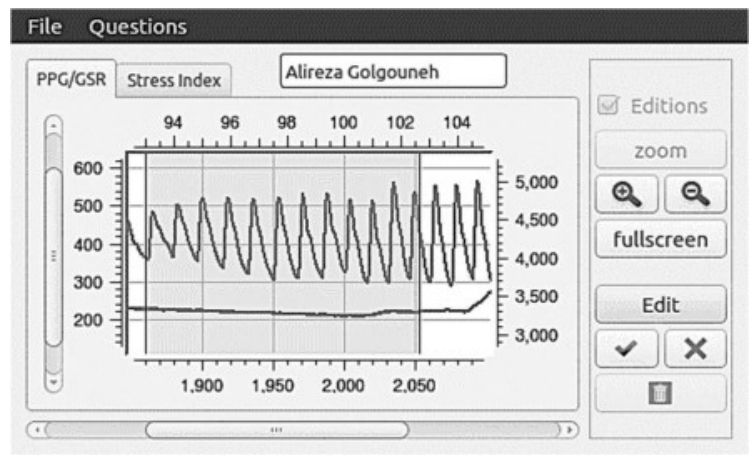

(شكل-19): فرم ويرايش آفلاين سيحنالها و شاخص استرسى : (Figure-19): Offline editing of the signals and stress index
كاربرى دستخاه ساختهشده در اين يروهش، از زبان +C+C و

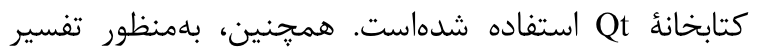

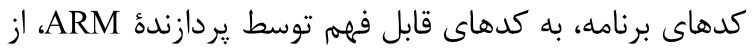

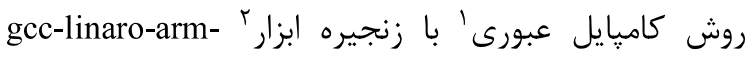

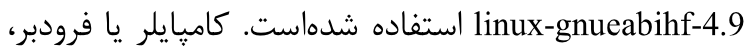
برنامه يا مجموعهاى از برنامههاى رايانهاى است كه متنى از

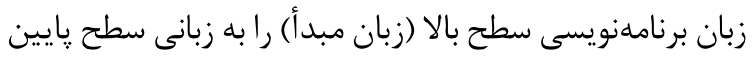
(زبان مقصد)، مثل اسمبلى يا زبان سطح ماشين، تبديل

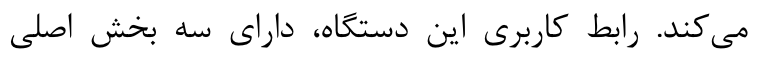
و و Simulation ،Real Time

$$
\text { مختصرى درباره قسمت داده شدهاست. }
$$

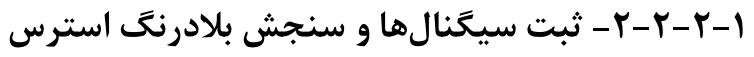
در بخش Real Time يا بلادرنگ، ابتدا اطلّلاعات شخصى كاربر

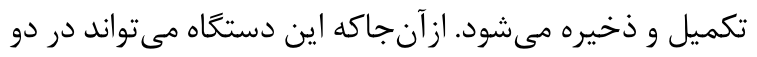

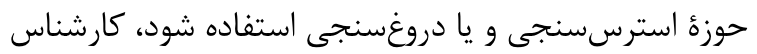
استرسسنج مىتواند در اين قسمت، سؤالاتى را تعيين كند تا داء هنگام مصاحبه از فرد يرسيدهشود. يكى ديكر از امكانات اين

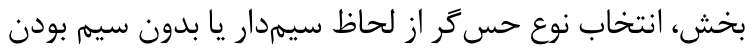

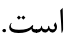
يس از انجام مراحل ذكرشده و واردكردن اطلاعات كاربر و انتخاب نوع حس

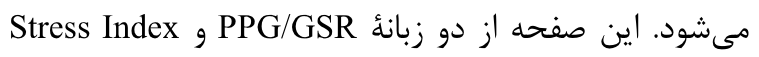

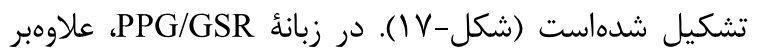
نمايش ضربان قلب، سيخنالهاى PPG (رنت آبى) و GSR

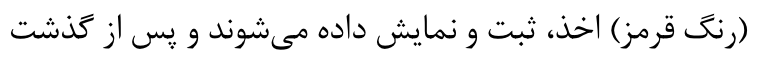

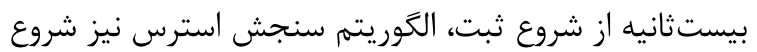
به يردازش سيخَال ها كرده و در زبانٔ Stress Index ميزان شاخص استرسى به صورت يك نمودار زيوسته نمايش

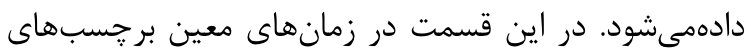
קيشفرضى را به سيخنالها اضافه يا هنگام ثبت استرسى، صداى محيط يا كاربر را مىتوان ذخيره كرد.

r-Y-Y-Y-Y - شبيهسازى مجدد يك ثبت استرسى

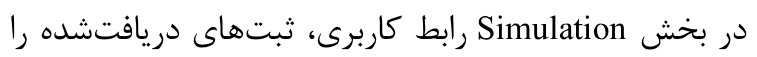
مىتوان شبيهسازى كرد؛ منظور از شبيهسازى، نمايش مجدد

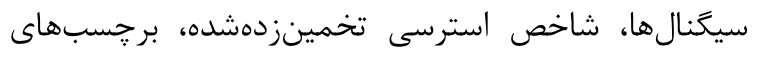

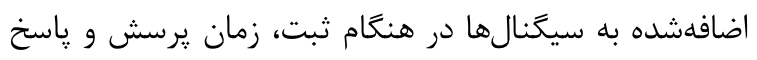

${ }^{1}$ Cross-Compile

${ }^{2}$ Toolchain 
استرس در فرد ادامه بِيدا كند، باعث بروز مشكلاتى خواهد

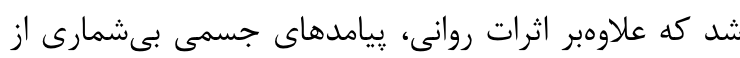
جمله سكته هاى مغزى، قلبى، فشارخون، يوكى استخوان، زخما

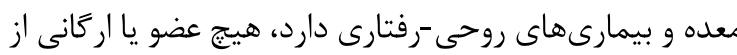
بدن از اثرات استرس در امان نيست. از اينرو ساخت يك ديك

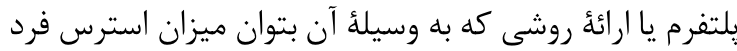

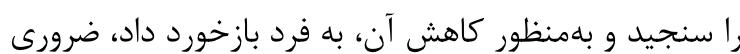
و مفيد است.

هدف اصلى با كمك اين يزوهش، طراحى و ساخت

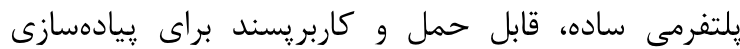

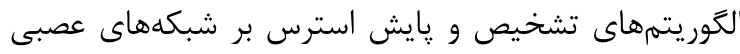

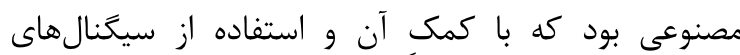
فتويلتيسمو گرافى (PPG) و هدايت الكتريكى يوست (GSR)، بتوان استرس فرد را تشخيص داد. بنابراين، در ساخت اين

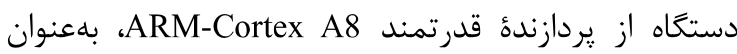

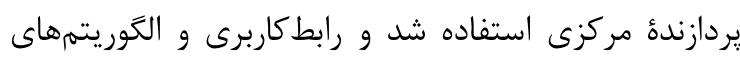

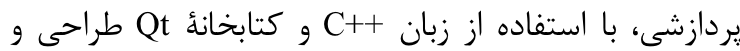

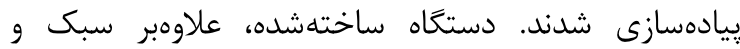

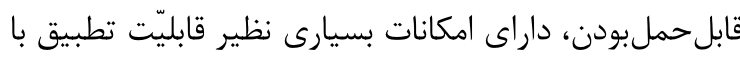

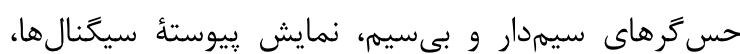

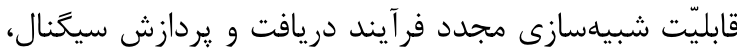
ضبط و پخش صدا، ذخيره اطلاعات شخصى افراد، امكان

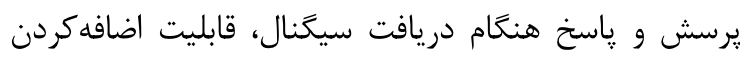

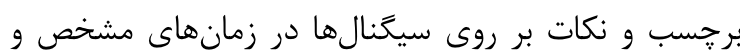
بسيارى از موارد ديخر است. در اين دستگاه، تخمين ميزان استرس فرد، بلصورت استر

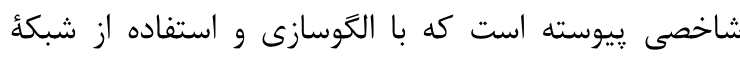

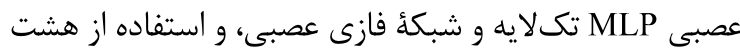
ويزگى استخراجشده از سيكنالهاى PPG و GSR انجام شدهاست. در مقايسه با شبكؤ عصبى MLP، شبكأ ANFIS عملكرد مناسبترى را دارد؛ بهطورى كه ميانگين همبستخى باستى

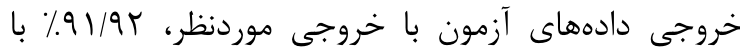

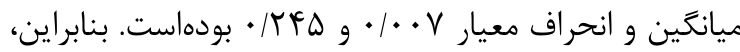

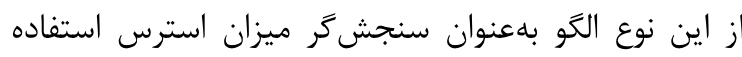

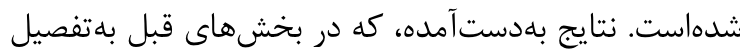

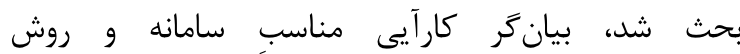
توسعهدادهده در اين يزوهش، بلمنظور سنجش استرس برمبناى سيكنال هاى حياتى است.

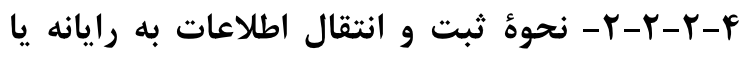
دستخاهى ديكر

از آنجا كه ممكن است، نياز به استفاده از ثبتهاى استرسى ديك انجامشده، در يزوهشهاى ديكر، يا در دستخاه مشابهى باشد،

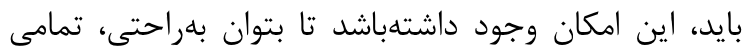

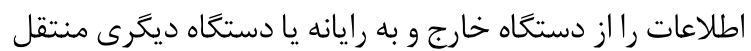
كرد. بدينمنظور، رابط كاربرى بهنحوى برناملنويسى شدهاست كه تمامى اطّلاعات هر ثبت كه شامل اطلّلاعات شخصى، برجسبهاى زدهشده بر روى سيخنال، شروع و پايان هر سؤال، فايل صوتى مصاحبه، دادههاى خام دريافتشده از حسكرها،

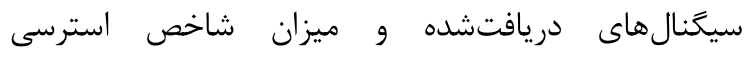
تخمينزدشده، هستند، در يوشهاى جداقانه كه با نامى

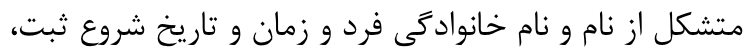

ذخيره مىشود.

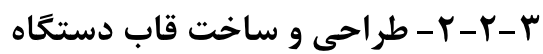
يكى از بخشهاى اصلى سختافزارى، طراحى قابى مناسب

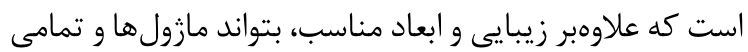
سختافزارها را در بركيرد و بهراحتى قابل حمل باشد.

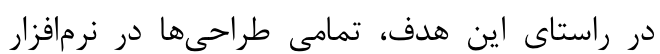

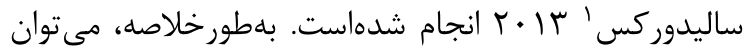
مر احل طراحى و ساخت قاب دستخاه را بهصورت زير خلاصه بلدئ كرد: - مر: 1. طراحى مكانيكى(CAD) مازولها و يردازندة مركزى و

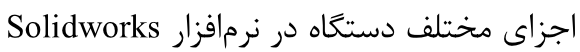
r. جينش CAD قطعات با درنظركرفتن ابعاد و جنبئ

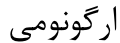
r. طراحى قاب (CAD) دستخاه

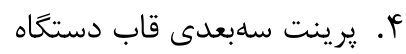
ه. مونتاز اجزاى مختلف دستكاه

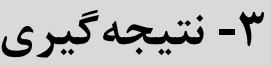

با توجّه به نفوذ استرس در جنبههاى گَوناتون زندگى برتلاطم امروز، بايد آن را بهعنوان بخشى از زندكى امروز بهشمار آورد.

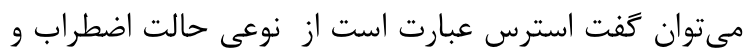

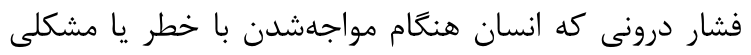
جدى، با ترشح هورمونهايى خود را براى مقابله با آنها آماده مىكند كه براى روند زندگى ضرورى نيز است؛ اما اخر اين

\footnotetext{
${ }^{1}$ Solidworks
} 
[11] A. Muaremi, B. Arnrich, and G. Tröster, "Towards Measuring Stress with Smartphones and Wearable Devices During Workday and Sleep," Bionanoscience, vol. 3, no. 2, pp. 172183,2013

[12] C. Epp, M. Lippold, and R. L. Mandryk, "Identifying emotional states using keystroke dynamics," in Proceedings of the SIGCHI Conference on Human Factors in Computing Systems, pp. 715-724, 2011.

[13] D. F. Dinges et al., "Optical computer recognition of facial expressions associated with stress induced by performance demands.," Aviat. Space. Environ. Med., vol. 76, no. 6 Suppl, pp. B172-82, 2005.

[14] A. Alberdi, A. Aztiria, and A. Basarab, "Towards an automatic early stress recognition system for office environments based on multimodal measurements: A review," J. Biomed. Inform., vol. 59, pp. 49-75, 2016.

[15] P. Zimmermann, S. Guttormsen, B. Danuser, and P. Gomez, "Affective computing-A rationale for measuring mood with mouse and keyboard," Int. J. Occup. Saf. Ergon., vol. 9, no. 4, pp. 539$551,2003$.

[16] M. Garbarino, M. Lai, D. Bender, R. W. Picard, and S. Tognetti, "Empatica E3-A wearable wireless multi-sensor device for real-time computerized biofeedback and data acquisition," in Wireless Mobile Communication and Healthcare (Mobihealth), 2014 EAI 4th International Conference on, pp. 39-42, 2014,

[17] A. Golgouneh, A. Bamshad, B. Tarvirdizadeh, and F. Tajdari, "Design of a new, light and portable mechanism for knee CPM machine with a user-friendly interface," In Artificial Intelligence and Robotics (IRANOPEN), pp. 103108. IEEE, 2016

[18] B. Cinaz, B. Arnrich, R. La Marca, and G. Tröster, "Monitoring of mental workload levels during an everyday life office-work scenario," Pers. ubiquitous Comput., vol. 17, no. 2, pp. 229239, 2013.

$$
\begin{aligned}
& \text { [19] ر. عارفى شيروانى، م. خليلزاده و و. سعادتيان، "مقايسٔ } \\
& \text { تحليل خطى و غيرخطى سيگنال تغييرات نرخ ضربان } \\
& \text { قلب بهمنظور كمىسازى سطح استرس با استفاده از } \\
& \text { الكوريتهم تكاملى و شبكهُ عصبى،“" بِردزش علائهم و داده، }
\end{aligned}
$$

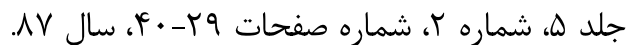

[19] R.A. Shirvan, M.A. Khalilzadeh, S.E. Tahami, and V. Saadatian, "Comparision of linear and nonlinear feaaturs of heart rate variability signal to quantification of stress level using genetic algorithem and neural network," Signal and Data Processing, vol. 5, no. 2, p.p. 29-40, 2009.

[20] C. Maaoui, A. Pruski, and F. Abdat, "Emotion

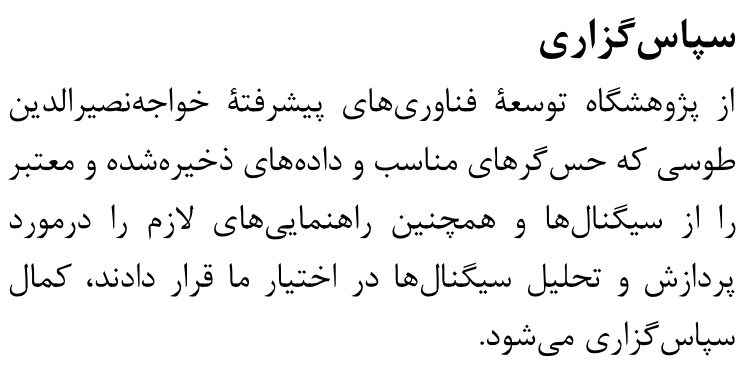

4- References

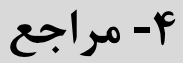

[1] J. Cacioppo, L. G. Tassinary, and G. G. Berntson, The Handbook of Psychophysiology, vol. 44., Cambridge University Press, 2007.

[2] H. Kurniawan, A. V Maslov, and M. Pechenizkiy, "Stress detection from speech and Galvanic Skin Response signals," Proceedings of the 26th IEEE International Symposium on ComputerBased Medical Systems. pp. 209-214, 2013.

[3] A. Kaklauskas et al., "Web-based biometric computer mouse advisory system to analyze a user's emotions and work productivity," Eng. Appl. Artif. Intell., vol. 24, no. 6, pp. 928-945, Sep. 2011.

[4] "Physiology," 2015. [Online]. Available: http:// www.oxforddictionaries.com/definition/english/ physiology.

[5] E. Risk and O. Report, OSH in figures: stress at work - facts and figures. Luxembourg,: European Agency for Safety and Health at Work, 2009.z

[6] M. Bickford, "Stress in the workplace: A general overview of the causes, the effects, and the solutions," Canadian Mental Health Association Newfoundland and Labrador Division, pp. 1-3, 2005.

[7] W. Liao, W. Zhang, Z. Zhu, and Q. Ji, "A realtime human stress monitoring system using dynamic bayesian network," IEEE Computer Society Conference on Computer Vision and Pattern Recognition (CVPR'05) - Workshops. p. 70, 2005.

[8] D. Carneiro, J. C. Castillo, P. Novais, A. Fernández-Caballero, and J. Neves, "Multimodal behavioral analysis for non-invasive stress detection," Expert Systems with Applications, vol. 39, no. 18, pp. 13376-13389, 2012.

[9] T. Hayashi, Y. Mizuno-Matsumoto, E. Okamoto, M. Kato, and T. Murata, "An fMRI study of brain processing related to stress states," World Automation Congress (WAC), pp. 1-6, 2012

[10] H. Lu et al., "Stresssense: Detecting stress in unconstrained acoustic environments using smartphones," Proceedings of the 2012 ACM Conference on Ubiquitous Computing, pp. 351360. ACM, 2012. 
Trans., vol. 6, no. 2, pp. 156-166, 2005.

[33] J. Hernandez, P. Paredes, A. Roseway, and M. Czerwinski, "Under pressure: sensing stress of computer users," in Proceedings of the SIGCHI conference on Human factors in computing systems, pp. 51-60, 2014.

[34] F.-T. Sun, C. Kuo, H.-T. Cheng, S. Buthpitiya, P. Collins, and M. Griss, "Activity-aware mental stress detection using physiological sensors," in International Conference on Mobile Computing, Applications, and Services, 2010, pp. 211-230.

[35] C. Setz, B. Arnrich, J. Schumm, R. La Marca, G. Tröster, and U. Ehlert, "Discriminating stress from cognitive load using a wearable EDA device," IEEE Trans. Inf. Technol. Biomed., vol. 14, no. 2, pp. 410-417, 2010.

[36] A. de Santos Sierra, C. S. Ávila, J. G. Casanova, and G. B. Del Pozo, "A stress-detection system based on physiological signals and fuzzy logic," Ind. Electron. IEEE Trans., vol. 58, no. 10, pp. 4857-4865, 2011.

[37] ر. عارفى شيروانى، م. خليلزاده، "يردازش و تحليل

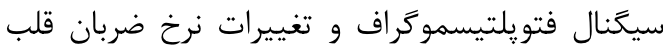

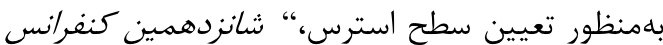

$$
\text { مهنلسسى برق، }
$$

[37]. R.A. Shirvan, M.A. Khalilzadeh, "Process and analysis of the photoplethysmography and heart rate variability signals to determine stress level," $16^{\text {th }}$ Iranian Conference on Electrical Engineering, 2008.

$$
\begin{aligned}
& \text { [38] ا. درخشان، م. خليلزاده، م. آذرنوش، ا. محمديان، }
\end{aligned}
$$

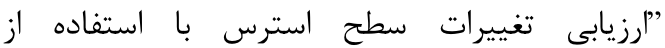

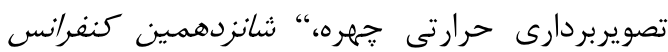

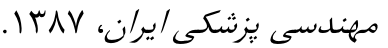

[38]. A. Derakhshan, M.A. Khalilzadeh, M. Azarnoosh, A. Mohammadian, "Evaluate the changes in stress level using facial thermal imaging," $16^{\text {th }}$ Iranian conference on Biomedical Engineering, 2008.

[39] K. Frank, P. Robertson, M. Gross, and K. Wiesner, "Sensor-based identification of human stress levels," in Pervasive Computing and Communications Workshops (PERCOM Workshops), 2013 IEEE International Conference on, pp. 127-132, 2013.

[40] M. Morris and F. Guilak, "Mobile heart health: project highlight," IEEE Pervasive Comput., vol. 8, no. 2, pp. 57-61, 2009.

[41] V. Alexandratos, M. Bulut, and R. Jasinschi, "Mobile real-time arousal detection," in 2014 IEEE International Conference on Acoustics, Speech and Signal Processing (ICASSP), pp. 4394-4398, 2014. recognition for human-machine communication," in Intelligent Robots and Systems, 2008. IROS 2008. IEEE/RSJ Inter-national Conference on, pp. 1210-1215, 2008.

[21] M. T. Quazi, S. C. Mukhopadhyay, N. K. Suryadevara, and Y. M. Huang, "Towards the smart sensors based human emotion recog-nition," in Instrumentation and Measurement Technology Conference (I2MTC), 2012 IEEE International, pp. 2365-2370, 2012

[22] K. Palanisamy, M. Murugappan, and S. Yaacob, "Multiple physiological signal-based human stress identification using non-linear classifiers," Elektron. ir Elektrotechnika, vol. 19, no. 7, pp. 80-85, 2013.

[23] J. Wijsman, B. Grundlehner, J. Penders, and H. Hermens, "Trapezius muscle EMG as predictor of mental stress," in Wireless Health 2010, pp. 155-163, 2010.

[24] S.-H. Seo, J.-T. Lee, and M. Crisan, "Stress and EEG. Convergence and hybrid information technologies," InTech. Available from http// www. intechopen. com/ books/ Converg. Stress., 2010.

[25] Y. Shi, M. Nguyen, P. Blitz, and B. French, "Personalized stress detection from physiological measurements," Int. Symp. Qual. Life Technol., no. September 2015, pp. 28-29, 2010.

[26] C. Z. Wei, "Stress emotion recognition based on RSP and EMG signals," in Advanced Materials Research, 2013, vol. 709, pp. 827-831.

[27] J. Zhai and A. Barreto, "Stress detection in computer users based on digital signal processing of noninvasive physiological variables," in Engineering in Medicine and Biology Society, 2006. EMBS'06. 28th Annual International Conference of the IEEE, pp. 1355-1358, 2006.

[28] V. Jeyhani, S. Mahdiani, M. Peltokangas, and A. Vehkaoja, "Comparison of HRV parameters derived from photoplethysmography and electrocardiography signals," in 2015 37th Annual International Conference of the IEEE Engineering in Medicine and Biology Society (EMBC), 2015, pp. 5952-5955.

[29] J. Peuscher, "Galvanic skin response (GSR)," 2In: TMSi. 2012.

[30] K. Peternel, M. Pogačnik, R. Tavčar, and A. Kos, "A presence-based context-aware chronic stress recognition system," Sensors, vol. 12, no. 11, pp. 15888-15906, 2012.

[31] K. Asai, "The Role of Head-Up Display in Computer-Assisted Instruction," arXiv Prepr. arXiv1001.0420, 2010.

[32] J. A. Healey and R. W. Picard, "Detecting stress during real-world driving tasks using physiological sensors," Intell. Transp. Syst. IEEE 
[55] J.-S. Jang, “ANFIS: adaptive-network-based fuzzy inference system," IEEE Trans. Syst. Man. Cybern., vol. 23, no. 3, pp. 665-685, 1993.

[56] L.-X. Wang, "A Course in Fuzzy Systems and Control, Prentice-Hall PTR," Englewood Cliffs, NJ, 1997.

[57] M. Saidi, H. Hassanpoor, and A. Azizi Lari, "Proposed new sign

al for real-time stress monitoring: Combination of physiological measures," AUT J. Electr. Eng.' vol. 49, no. 1, pp. 11-18, 2017.

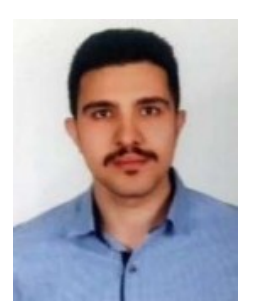

عليرضا كل ${ }^{2}$ مقطع كارشناسى، درسال بوسا در

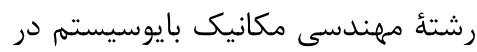

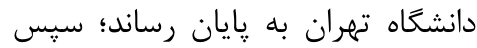
بهعنوان دانش آموخته برتر، تحصيلات بهان خود را در رشتهٔ مهندسى مكاترونيك

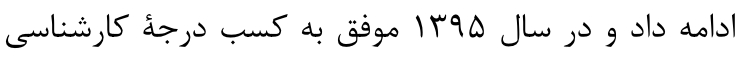

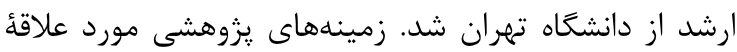
ايشان عبارتند از: سامانههاى مكاترونيكى و رباتيكى، يردازش سيخنال و تصوير، هوش مصنوعى و ياد ئرى ماشين.

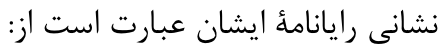

golgouneh@ut.ac.ir

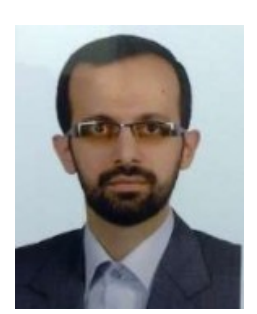

بهرام تارويردىزاده تحصيلات خود در مقطع دكتراى تخصصى را در سال

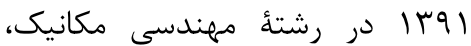
كرايش طراحى كاربردى، در دانشعاه تهران سيرى كرد. ايشان همماكنون استاديار دانشكدة علوم و فنون نوين دانشعاه تهران هستند و تخصص اصلى ايشان، مكاترونيك، رباتيك، ديناميك، كنترل و سامانههاى Embedded است.

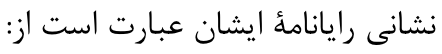

bahram@ut.ac.ir
[42] "Research Center for Development of Advanced Technologies." [Online]. Available: http://en.redat.ir.

[43] J. A. Healey, "Wearable and automotive systems for affect recognition from physiology." Massachusetts Institute of Technology, 2000.

[44] M. E. Dawson, A. M. Schell, and D. L. Filion, "7 the electrodermal system," Handb. Psychophysiol., vol. 159, 2007.

[45] M. Bolanos, H. Nazeran, and E. Haltiwanger, "Comparison of heart rate variability signal features derived from electrocardiography and photoplethysmography in healthy individuals," in Engineering in Medicine and Biology Society, 2006. EMBS'06. 28th Annual International Conference of the IEEE, pp. 4289-4294, 2006.

[46] W.-H. Lin, D. Wu, C. Li, H. Zhang, and Y.-T. Zhang, "Comparison of heart rate variability from PPG with that from ECG," in The International Conference on Health Informatics, pp. 213-215, 2014.

[47] J. Rand, A. Hoover, S. Fishel, J. Moss, J. Pappas, and E. Muth, "Real-time correction of heart interbeat intervals," IEEE Trans. Biomed. Eng., vol. 54, no. 5, pp. 946-950, 2007.

[48] G. G. Berntson and J. R. Stowell, "ECG artifacts and heart period variability: don't miss a beat!," Psychophysiology, vol. 35, no. 1, pp. 127-132, 1998.

[49] P. D. Welch, "The use of fast Fourier transform for the estimation of power spectra: A method based on time averaging over short, modified periodograms," IEEE Trans. audio Electroacoust., vol. 15, no. 2, pp. 70-73, 1967.

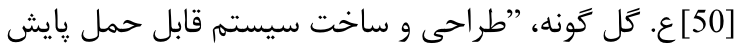

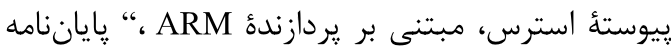

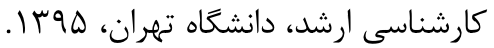

[50] A. Golgouneh, "Design and development of a portable system to continuous stress monitoring system using ARM processor," M.S. Thesis, University of Tehran, 2016.

[51] M. A. Hall, "Correlation-based feature selection of discrete and numeric class machine learning," 2000.

[52] T. M. Geronimo, C. E. D. Cruz, E. C. Bianchi, F. de Souza Campos, and P. R. Aguiar, "MLP and ANFIS Applied to the Prediction of Hole Diameters in the Drilling Process,". INTECH Open Access Publisher, 2013.

[53] P. Davis, "Levenberg-marquart methods and nonlinear estimation," Siam News, vol. 26, no. 6, pp. 1-12, 1993.

[54] L. A. Zadeh, "Fuzzy sets," Inf. Control, vol. 8, no. 3, pp. 338-353, 1965. 